\title{
Compulsory and Voluntary Annuities Markets in the UK
}

\author{
Edmund Cannon* and Ian Tonks**
}

\author{
Paper No 10/o1 \\ January 10
}

*Department of Economics, University of Bristol, 8 Priory Road, Bristol BS8 1TN: edmund.cannon@bristol.ac.uk. ${ }^{* *}$ Xfi Centre for Finance and Investment, University of Exeter, Streatham Court, Rennes Drive, Exeter, EX4 4PU i.tonks@exeter.ac.uk

Part of this work arose out of a project at the Department of Work and Pensions, and was started while Tonks was visiting the Bank of England as a Houblon-Norman fellow, and he would like to thank the Bank for its hospitality during his fellowship. We should like to thank Tatiana Goussarova and Alexa Hime for entering the data. We should also like to thank David Blake (CASS Business School), Billy Burrows (Willam Burrows Annuities), Rebecca Driver (ABI), Brian Harrison, George Hawkins (both Friends Provident), Stuart Hicks (FSA), Sarah Meagher (DWP) and Helen McCarthy (formerly of the ABI) for assistance with the data, comments and observations. The paper has also benefited from comments made at seminars held at the Bank of England, the Department of Work and Pensions, the Association of British Insurers, and Royal Economics Society Conference April 2009. Any errors and views expressed in the paper remain the responsibility of the authors. 


\begin{abstract}
This paper describes the operation of both the compulsory pension annuity and voluntary annuity markets in the UK. The paper reports on the movement of UK annuity price quotes in the voluntary market from 1957-2009, and in the pension annuity market from 1994 to 2009, and examines whether annuities were fairly priced over this period. The paper computes the money's worth of annuities, and finds that on average the money's worth in the voluntary market over the sample period for 65 -year old males has been a very high $98 \%$. In the larger compulsory pension annuity over a shorter sample period we estimate that the money's worth for 65 -year old males has been $89 \%$, and for 65 -year old females has been a similar but slightly larger 90\%. Taking into account load factors associated with annuity contracts and in comparison with other financial and insurance products this implies that annuities are fairly priced. However the value of the money's worth is sensitive to the assumptions made about life expectancy, and we explain the assumptions made about the appropriate life tables to apply to annuitants in these annuity markets. There is some evidence that money's worth has fallen since 2002. We discuss a number of factors that could have effected the fall in money's worth, including: changes in insurance regulation; changes in industrial concentration; an insurance cycle; pricing of mortality uncertainty and the growth in the impaired lives market.
\end{abstract}

JEL Classification: E62, G14, H55

Keywords: Annuities, annuity markets, pension replacement ratio 
This paper discusses the operation of both the compulsory pension annuity and voluntary annuity markets in the UK, and examines whether annuities in these markets were fairly priced. The UK is unusual in having two distinct annuity markets: a voluntary segment called the Purchased Life Annuity (PLA) market, and a compulsory section called the Compulsory Purchase Annuity (CPA) or pension annuity market. The UK government requires that anyone who has saved in a tax-privileged private pension, must annuitize 75 per cent of their pension wealth in the CPA market at retirement. The voluntary annuities market had existed for many years, but was given a boost with a more favourable tax-treatment of annuity income in the 1956 Finance Act, and we provide a time series of voluntary annuity rates from 1957-2009. The same Act introduced the pension annuity market, but it was the Social Security Act 1988 that provided strong tax incentives for individuals to save in individual defined contribution pension schemes, and this has resulted in a strong growth for personal pensions. After a delay (because of the lagged nature of accumulating a pension fund), the compulsory annuitization requirement has resulted in an increased demand for pension annuities, and we also construct a time series of UK annuity price quotes in the pension annuity market from 1994 to 2007 . We report on the fall in annuity rates in both markets that has occurred since 1994. If the fall in annuity rates had happened while everything else remained the same, then a consequence would be that the value-for-money of annuities would have fallen. However, over the same period bond yields have fluctuated, and there have been substantial upward revisions in projected life expectancy. As people live longer, a given sum of money paid for an annuity has to finance a longer stream of income and so the zero-profit condition for annuity provides means that income per year has to fall. This reduction in annuity rates is unavoidable: the relevant issue is whether the magnitude of the fall in annuity rates in the recent past is appropriate given the increases in life expectancy and fluctuations in the appropriate discount rates. 
This paper addresses whether the fall in annuity rates over the period 1994 to 2009 is larger than could be justified by the fundamental changes in longevity and bond yields. Our analysis centres on calculations of the "money's worth" which is the conventional measure to determine whether annuities are fairly priced, and assesses whether the expected present value of the annuity payments equals the price of the contract.

In Section 2 we provide a brief overview of the UK annuity markets, and in Section 3 we define the money's worth and review existing research on the pricing of annuity contracts. Section 4 discusses the life expectancy projections and other data issues and Section 5 provides the results of our money's worth calculations. In Section 6 we discuss a number of factors that could have affected the fall in money's worth, including: changes in insurance regulation; changes in industrial concentration; an insurance cycle; pricing of mortality uncertainty and the growth in the impaired lives market. Section 7 concludes.

\section{UK ANNUITY MARKETS}

A life annuity is a financial product making a stream of income payments while the annuitant is alive. The simplest form of annuity consists of a single payment (sometimes called a "premium" or "consideration") from the annuitant to the annuity provider and thereafter the annuity provider pays a constant stream of regular payments (monthly, quarterly or annually) until the annuitant's death. More complicated products could have the stream of payments rising over time by a fixed amount (an escalating annuity) or rising in line with inflation (real annuities). It is also possible to buy an annuity where the first five years' payments are made regardless of whether the annuitant lives or dies but payments thereafter are only made if the annuitant is alive (a guaranteed annuity - if the annuitant dies before five years the payments are made to the annuitant's estate). Guaranteed annuities with payments guaranteed for up to ten years are also available. If an annuitant dies before the total payments received sum to the purchase price then it is possible to have the difference 
repaid as a lump sum to the annuitant's estate (a value protected annuity). A detailed description of these various products is provided in Cannon and Tonks (2008).

It is usual for people to buy annuities at retirement to provide a pension income. A life annuity converts the retirement fund into an income stream payable to the annuitant until their death, and hence insures the individual against insufficient assets to finance consumption due to longevity risk. Yaari (1965) demonstrated in a life-cycle model of saving that risk-averse individuals should annuitise all of their capital at retirement, since annuititisation protects the individual from longevity risk. However, Brown, Mitchell, Poterba and Warshawsky (2001) note that the private annuity markets are typically small, which is inconsistent with agents getting large utility gains from purchasing annuities. Poterba (2001) and Brown (2001) suggest a number of explanations for this "annuity puzzle". Annuities may be expensive, either due to high administrative costs for annuity providers (referred to as "load factors") or to mis-pricing. Elderly people may prefer to hold their wealth in more liquid assets for precautionary reasons or because they wish to bequeath their wealth to the next generation. Demand for private annuities may be low because many people receive a state pension which is itself a form of annuity. In the UK individuals at retirement have a significant proportion annuity equivalent wealth in state pension rights. The Pension Commission (2004 [182]) reports that only those individuals whose labour income exceeds about £25, ooo per year have a sizeable amount of their total wealth in assets other than their state pension. Annuity markets may suffer from a particular problem of "adverse selection" - since longer-lived individuals benefit more from an annuity than shorter-lived individuals, and shorter-lived individuals may leave the market. Finally, individuals may dislike annuities for a range of behavioural factors.

Figure 1: Growth in Annuity Sales 1994-2006 (Source: ABI) 


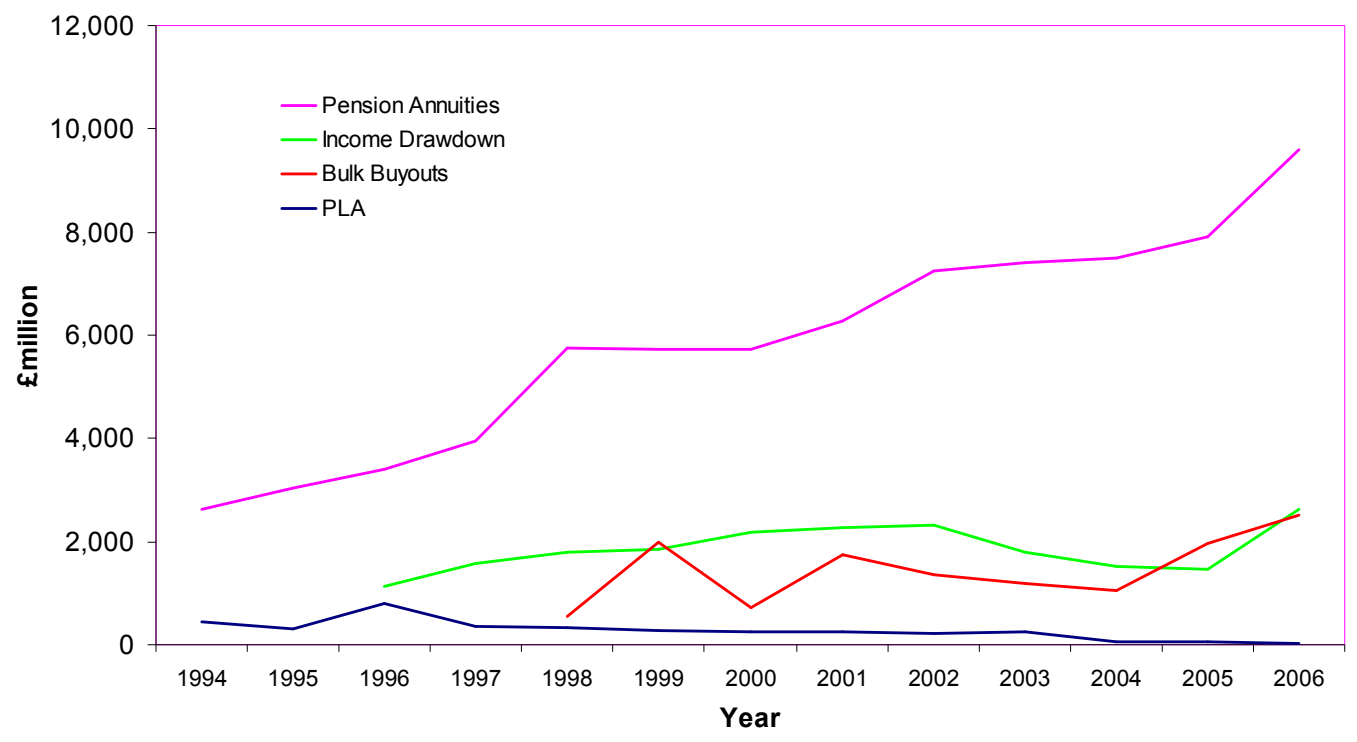

In the UK there is both a compulsory (Compulsory Purchase Annuity, CPA) pensions annuity market and a voluntary (Purchased Life Annuity, PLA) market. The UK government requires that anyone who has saved in a taxprivileged private pension, must annuitize 75 per cent of their pension wealth. However, the annuitization rules allow a private pension saver to defer the purchase of an annuity, via income draw-down (or phased withdrawal) which generates an income by drawing from the fund itself.

Figure 1 shows the growth in UK annuities and income drawdown over the period 1994-2006. By 2006, the compulsory (CPA) market had grown to $£ 9.58$ billion worth of annuity premiums. In contrast, the voluntary (PLA) market only amounted to $£ 40.8$ million worth of sales, and the diagram shows that the PLA market has shrunk as the CPA market has grown, probably reflecting some substitution between compulsory and voluntary annuities. The bulk annuity market (where an annuity provider acquires a package of individual pension liabilities, typically, because the sponsor of a defined benefit occupational scheme has become insolvent), has been volatile, but as yet there has not been the predicted surge in transfers from defined benefit schemes to bulk buy-outs as suggested in the Pension Commission Reports. Income drawdown continues to represent a significant alternative to annuitization. 
Table 1: Scenarios for the size of the annuity market, (estimated annual flows: $€$ billion)

\begin{tabular}{lcccc}
\hline & 2002 & \multicolumn{3}{c}{2012} \\
\hline & & Low & Medium & High \\
Individual annuities & 7.2 & 16.6 & 18.1 & 19.7 \\
Drawdown & 2.3 & 5.3 & 5.8 & 6.3 \\
Bulk buyout & 1.4 & 1.5 & 35.4 & 128.1 \\
\hline
\end{tabular}

Source: Pension Commission (2005, Figure 5.16)

Watson-Wyatt (2003) and Wadsworth (2005) examine a number of scenarios for the growth of annuity demand over the ten-year period 2002-2012, reproduced in Table 1 taken from Figure 5.16 in Pensions Commission (2005). According to the Pension Commission's Second Report and reiterated in HM Treasury (2006), the main driver in these estimates is the maturity of individual and company defined benefit schemes. As increasing numbers of personal pension schemes mature, this will result in an increased demand for pension annuities. Table 1 shows that the demand for annuities could increase from about $£ 7$ billion in 2002 to between $£ 16$ - $£ 20$ billion by 2012. But these numbers could increase dramatically if existing defined benefit schemes are closed and replaced by bulk buyouts of annuities. Then depending on the extent of this switch, the demand for annuities in the UK could increase by up to $£ 128$ billion.

The Pensions Commission (2006) proposed the introduction of a national pensions savings scheme as part of a wider package of pension reform, and these recommendations are being implemented in the proposed "Personal Accounts" outlined in Department of Work and Pensions (2006). This new pension scheme is a defined contribution scheme, and this will also need to be annuitized at retirement. ${ }^{1}$ The Pensions Commission (2005) also suggests that if the proposed national pension savings scheme successfully targets that group of

\footnotetext{
${ }^{1}$ Legislation for personal accounts, as well as automatic enrolment and minimum employer contributions is going through parliament at the time of writing this document.
} 
the population who currently are not provided for, they estimate that in the steady state this will represent an annual demand for annuities of $£ 13$ billion by the year 2040 at current earnings levels. This demand represents an additional increase on the numbers in Table 1 and Figure 1.

All of this evidence suggests that the demand for annuities in the UK will continue to rise substantially in the coming years, and therefore examining the functioning of the annuities market is relevant and timely for public policy. The UK government has emphasized its commitment to the compulsory annuitization requirements (Department of Work and Pensions, 2002; HM Treasury, 2006) that at least 75 per cent of the funds in a tax-efficient pension scheme should be used to finance a pension income, which is referred to as "securing" an income since A-day in April 2006. Though, the Pensions Commission notes that any capacity problems in the compulsory annuities market could be eased by allowing a relaxation of these rules, or by encouraging delayed retirement.

\section{Annuities and Taxation}

The developments of both voluntary and compulsory annuity markets in the UK have been affected by the taxation of annuity payments and the treatment of accumulated pension savings. Cannon and Tonks (2008) document the history of voluntary annuities. After a long period of stagnation in the early $2 \mathrm{O}^{\text {th }}$ century the UK annuities market was given a dramatic boost under the 1956 Finance Act which implemented the main recommendations of the 1954 Millard Tucker No. 2 Committee on the introduction of tax efficient personal pensions for the self-employed. This meant that the self-employed were treated the same as the employed sector who had enjoyed the benefits of tax efficient occupational pension schemes for a number of years.

Following the Act, individuals could obtain tax relief on contributions into an approved pension contract, and at retirement would be required to annuitize the fund that had been built up, through a new compulsory-purchase annuities 
market for those who had built up a personal pension fund, distinct from the existing voluntary annuities market. Further, the returns to investments in the pension fund of life-assurance companies during the accumulation part of the pension contract would be exempt from tax.

An additional part of the 1956 Act also affected the tax treatment of voluntary annuities: a fixed proportion of the annuity payment for purchased life annuities was to be regarded as a run-down of capital, and an annuitant would only be liable for income tax on the balance. These changes stimulated the demand for annuities in the UK, and Table 2 shows the sales of voluntary annuities averaged over 5-yearly intervals from the 1950 s onwards. The numbers of annuities purchased each year vary greatly, though the value of the lump sum used to purchase an annuity contract has grown steadily from $£ 106$ million in the late 1960 s to $£ 650$ million in the first half of the 1990 . The overall trend increase during this period was due to the increase in private pensions that were reaching the point of retirement. 
Table 2: Growth in number and value of purchased life annuities, pension annuities and outstanding personal pension schemes 1954-2005: Annual averages over successive 5-year periods

\begin{tabular}{|c|c|c|c|c|c|c|c|c|c|c|c|}
\hline & $1951 / 55$ & $1956 / 60$ & $1961 / 65$ & $1966 / 70$ & $1971 / 75$ & $1976 / 80$ & $1981 / 85$ & $1986 / 90$ & $1991 / 95$ & $1996 / 00$ & $2001 / 2005$ \\
\hline \multicolumn{12}{|c|}{ Panel A: New Purchased Life Annuities (Immediate and Deferred) (Voluntary Market) } \\
\hline $\begin{array}{l}\text { No. of new annuity policies per year } \\
(000 \text { s })\end{array}$ & . & . & 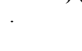 & 33.8 & 173.2 & 67.6 & 84.2 & 67.8 & 65.4 & 13.8 & 3.1 \\
\hline $\begin{array}{l}\text { Premiums on new immediate annuity } \\
\text { policies }(£ \mathrm{~m})\end{array}$ & . & . & . & 106.0 & 235.3 & 159.6 & 394.5 & 432.2 & 650.4 & 444.8 & 163.7 \\
\hline Annuity pay-outs per annum (£m) & 0.7 & 1.6 & & 12.7 & 44.0 & 25.1 & 66.2 & 80.5 & 129.8 & 39.2 & $\mathrm{n} / \mathrm{a}$ \\
\hline \multicolumn{12}{|c|}{ Panel B: New Pension Annuities (Compulsory market) } \\
\hline Premiums on new immediate pension & nuities $(£ \mathrm{~m}$ & illion) & & & & & & & $2,794.6$ & $5,178.4$ & 7,269 \\
\hline Pension annuity pay-outs per annum & & & & & & & & & 276.4 & 446.2 & $\mathrm{n} / \mathrm{a}$ \\
\hline \multicolumn{12}{|l|}{ Personal Pensions in Force } \\
\hline No. of Policies (000s) & . & 83.9 & & . & 620.0 & $1,309.4$ & $3,151.4$ & $8,835.2$ & $17,916.0$ & $20,810.2$ & $22,900.8$ \\
\hline Yearly premiums ( $(\mathrm{fm})$ & . & 10.6 & & . & 68.0 & 212.6 & 758.1 & $2,451.6$ & $4,876.2$ & $6,497.6$ & $9,236.0$ \\
\hline
\end{tabular}

Source: Life Offices' Association; Association of British Insurers

The combination of various forms of personal and occupational pensions, together with frequent changes in regulation and tax policy meant that the system of taxation for pensions was highly confusing by the beginning of the 21st Century. The Government Green Paper (DWP, 2002) recognized this confusion and the consequent 2004 Finance Act simplified the system: changes came into effect on 6 April 2006, commonly referred to as 'A-day', under which the tax system in the UK was changed to a lifetime allowance. At retirement the maximum pension fund which bears no additional tax liability was set at £1.5million on A-day, rising annually thereafter. The maximum amount that could be paid into this pension fund was $£ 215$, ooo per year. This means that an individual with a large number of pension schemes, which might have had different tax rules and annuitization requirements, was subsequently able to aggregate the entire fund and buy a single annuity.

In addition under the A-day changes the compulsion to purchase an annuity was altered in several ways: it was strengthened by raising the minimum pension age to 55 (effective in 2010); but weakened by increasing access to pension funds through means other than an annuity. Following A-day, there are now three ways in which a tax-privileged pension may be accessed: a) secured income; b)unsecured income; and c) alternatively secured income

According to regulations laid down by Her Majesty's Revenue and Customs (HMRC), securing an income can be achieved either by purchasing an annuity 
in the "compulsory purchase" market (secured income) or drawing down a tightly prescribed income from the pension fund (alternatively secured income). However, the requirement to secure an income only requires that it be secure by the age of 75 , and an individual can choose to have unsecured income in the period between retirement and age 75 . Unsecured income is also referred to as income drawdown.

Under HMRC rules, the amounts of the three types of allowable pension income that the pensioner can receive depends on the annuity rate. With secured income (buying an annuity) this is obvious. With an unsecured income before 75 , the maximum amount drawn in each year is 120 per cent of the best level single-life annuity payment at the respective age and sex available in the compulsory purchase market (these rates are collected and published by the FSA). With alternatively secured income (post age 75), it is compulsory to draw between 65 and 90 per cent of the best annuity rate aged 75, and payments received outside this range are taxed at 40 per cent. The justification for the requirement to secure income by 75 is that savings in these pension plans are tax-advantaged, and that the reason for the tax relief in the first place is to encourage individuals to save for a pension. ${ }^{2}$

\section{DEFINITION OF THE MONEY'S WORTH}

To calculate the fair vale of an annuity we can calculate the expected discounted annuity payments promised by the annuity provider, based on the annuity rates that we have collected and compare this value with the actual cost. This statistic is called the "money's worth". It is the ratio of the expected present value of the flow of payments made by an annuity to the money paid for an annuity. For a general discussion of the calculation of the money's worth see the introduction to the collection of papers in Brown et al (2001).

\footnotetext{
${ }^{2}$ With unsecured income and alternatively secured income there are further restrictions or tax considerations for any capital sum left on the death of an individual: these are to discourage using unsecured income or alternatively secured income to effect inter-generational transfers.
} 
To calculate the money's worth approach: define the annuity rate $A_{\mathrm{t}}$ as the annuity payment received by an individual made per year per $£ 1$ purchase price in year $t .^{3}$ The expected present value of this annuity stream is called the money's worth. For a level annuity with no guarantee period, this can be calculated using

$$
\begin{aligned}
\text { Money's Worth } & \equiv A_{t}\left\{\frac{\pi_{t, t+1}}{1+R_{t, 1}}+\frac{\pi_{t, t+2}}{\left(1+R_{t, 2}\right)^{2}}+\mathrm{L}\right\} \\
& =A_{t} \sum_{i=1}^{i=T} \pi_{t, t+i}\left(1+R_{t, i}\right)^{-i}
\end{aligned}
$$

where $\pi_{t, t+i}$ is the probability of someone living $i$ more periods, believed in period $t$. $T$ is chosen so that $\pi_{t, t+T} \approx 0$ and $R_{t, i}$ is the appropriate discount rate in period $t$ for payments received in period $t+i$, expressed at an annual rate.

Notice that annuitants of different ages or sexes would have different values of $\pi_{t, t+i}$ since the probability of living a given length of time depends upon both age and sex. Clearly the annuity rate $A_{t}$ will also depend upon age and sex.

We calculate the money's worth using the term structure of interest rates at date $t$ and expectations of survival probabilities $\pi_{t, t+i}$ that we believe were available at time $t$.

With a zero load factor, under fair pricing the money's worth would be exactly equal to unity, and hence money's worth will reflect whether annuities are fairly priced. However, any positive load factor will result in the money's worth being less than unity. ${ }^{4}$

\footnotetext{
${ }^{3}$ It is possible for the annuity rate to depend upon the purchase price as discussed in Cannon and Tonks (2005).

${ }^{4}$ Typical costs incurred by an annuity provider and thus included in the load factor are: the administration costs of sale and delivery of the annuity contracts, including the payments system; the transactions costs of purchasing assets to match the liability incurred by the insurance company when it sets up the
} 
A number of studies have examined the extent to which annuity prices are actuarially fair. Mitchell, Poterba, Warshawsky and Brown (1999) suggest that the market is approximately efficient and that annuities are not actuarially mispriced in the USA. In their analyses of the UK annuity market Murthi, Orszag and Orszag (1999), Finkelstein and Poterba (2002) and Cannon and Tonks (2004a, 2009) all report similar results that annuities are approximately fairly priced in the UK by computing an annuity's money's worth. ${ }^{5}$

Finkelstein and Poterba (2002) calculate the money's worth of voluntary annuities for 65-year old men, to be 99 per cent, using data from a crosssectional sample of annuity providers in the year 1998. In comparison, Murthi, Orszag and Orszag (1999) reported a figure of 93 per cent, and Cannon and Tonks' (2004a) calculated a value of 98 per cent in the same year. Murthi et al (1999) also provide money's worth estimates of 100 per cent in 1990 and 92 per cent in 1994: Cannon and Tonks' (2004a) analogous figures are 98 per cent and 89 per cent. Cannon and Tonks' (2004a) figure of 98 per cent for 1990 is based upon the money's worth calculated using the a(90) table, but using the IM80 table (which was only published in that year), the figure would be 103 per cent. Thus over a period of eight years, using different estimates of life expectancy and using different data sets of annuity rates the range of estimates for the money's worth of just one type of annuity is quite large, varying from 89 per cent to 103 per cent

Finkelstein and Poterba (2002, 2004) specifically assess the degree of adverse selection in annuities markets, and find evidence of adverse selection in the voluntary annuity market. They note that it is difficult to distinguish between adverse selection and passive selection (purchasers of annuities tend to be richer and therefore longer-lived), and recognise the limitations of their small

annuity contract and all of the on-going costs of managing these assets; and the costs arising from the remaining risks faced by the annuity provider.

${ }^{5}$ James and Song (2001) report that annuities are fairly priced in a number of other countries. 
sample from a single annuity provider. Cannon and Tonks (2004a) assess the fair-pricing of UK annuities over a much longer time period 1957-2002, and for data from a wide range of annuity providers. They report that over the whole period 1957-2002, the average money's worth of voluntary annuities was 97 per cent and conclude that annuities are fairly priced over this time period. Cannon and Tonks (2009) computes the money's worth of compulsory annuities over the period 1994-2007, and find that on average the money's worth over the sample period for 65-year old males has been 90 per cent, and for 65-year old females was a similar but slightly larger 91 per cent.

\section{DATA FOR MONEY'S WORTH CALCULATIONS}

As can be seen in Section 3, three data series are needed for our money's worth calculations: annuity rates, interest rates and survival probabilities. In this section we discuss each data series in turn.

\subsection{Annuity rate data: Purchased Life Annuities (Voluntary)}

The only long-run time series of annuity rates for the UK is that constructed by Cannon and Tonks (2004b) for the voluntary annuities market for the period 1957-2002, which provides a detailed discussion of the voluntary market data. This data are primarily for level immediate voluntary annuities purchased for 1957 to 2002: data from 1973 onwards are for annuities with a 5-year guarantee and earlier data have no guarantee. According to Stark (2002) over 70 per cent of purchased annuities are level annuities, so the series are reasonably representative: more importantly historical data are not available for any other types of annuity. The data were collected from a series of trade magazines such as Pensions World and Money Management for the later period and The Policy for the earlier period, and are for various annuity providers for both men and women of different ages. In the current paper we update this data using quoted annuity rates for the voluntary sector provided by Moneyfacts up to March 2009. This enables us to construct a single series of average annuity rates in the 
voluntary market from 1957-2009. Annuity prices are usually quoted in the form of an annual annuity payment of $£ X$ per $£ 10$,ooo purchased, which we refer to as an annuity rate of X/10o per cent. In most of our analysis we use the average annuity rate across firms calculated from these data, although in practice annuitants may purchase only the higher priced annuities.

Figure 2 plots a time series of voluntary rates for men aged 65 and 70 , and for women aged 65, over the period 1994 to 2009 . It can be seen that annuity rates for men are consistently higher than for women of the same age; and that annuity rates are higher as age increases. Age and sex are two personal characteristics that annuity-providers condition on when quoting annuity prices, since life expectancy of women is higher than men, and of younger adults is higher than older adults. The striking aspect of this graph is the extent to which the series move together: we should expect this since the major cause of variation in annuity rates over a period as short as this is the variation in the entire term structure of interest rates - and clearly all annuity rates at any given point in time are based on the same term structure of interest rates. ${ }^{i}$ 
Figure 2: Voluntary annuity rates by age and gender

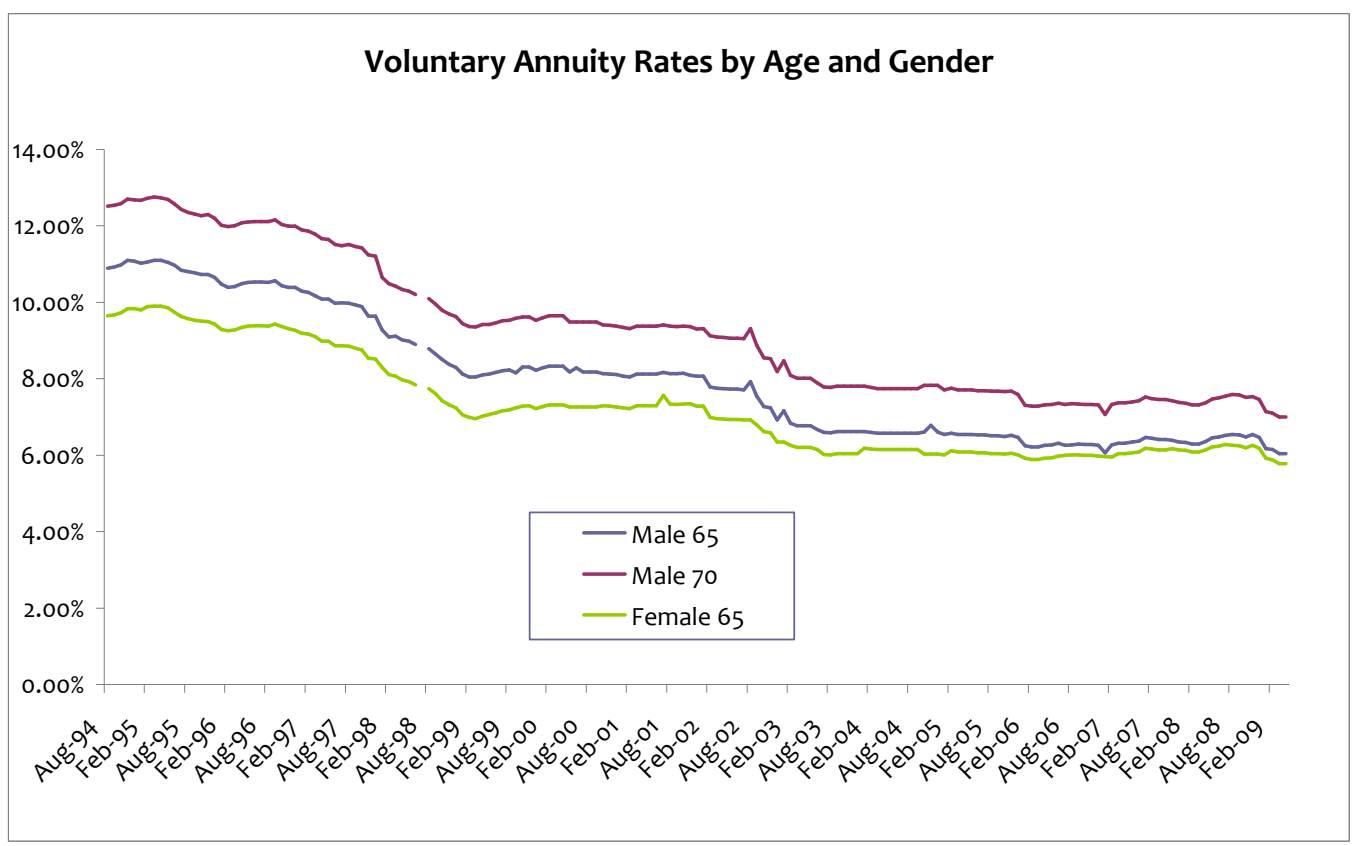

Figure 3 illustrates an annual annuity rate series for men aged 65 over a longer time period; and for comparison, a 10-year bond yield is also plotted as a representative long term interest rate. Descriptive statistics are presented in Table 2 for three sub-periods and also for the period as a whole (the annuity series for 1957 to 2009 created by splicing the series together). As can be seen from Figure 3, the series are highly correlated and the difference between them appears to be falling over time. 
Figure 3: Voluntary annuity rates for men aged 65 and Bond Yields

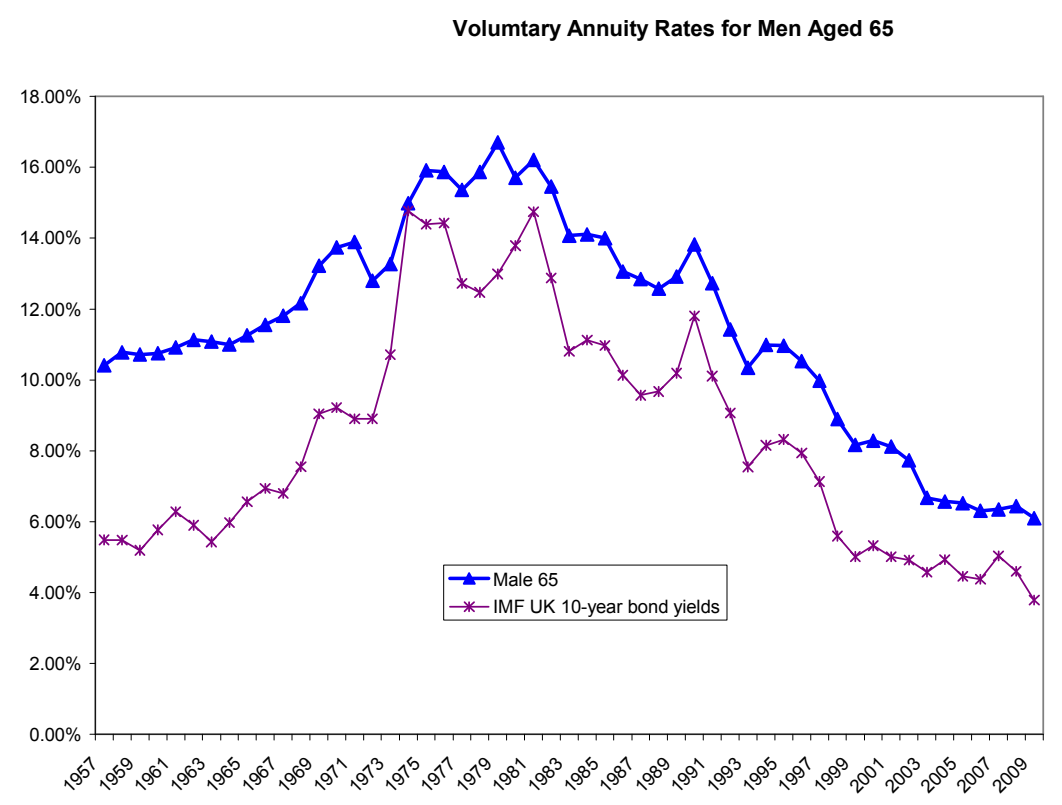

The long-term bond yield was roughly the same in both 1957 and 2009, making comparison of the beginning and end of the period straightforward. Although bond yields were the same, annuity rates were considerably lower in 2009 than in 1957. Cannon and Tonks (2004a) show that all of this narrowing is due to increases in longevity: as life expectancy increases the gap between the annuity rate and the bond yield ('mortality drag') will narrow. ii 
Table 2: Annual Time Series Properties on Voluntary Annuity and Bond Yields 1957-2009

\begin{tabular}{|c|c|c|c|}
\hline & $\begin{array}{l}\text { Annuity Rate } \\
(\%)\end{array}$ & $\begin{array}{l}\text { 10-year UK } \\
\text { bond yield } \\
\text { (IMF) } \\
(\%)\end{array}$ & $\begin{array}{l}\text { Difference } \\
\text { between } \\
\text { Annuity Rate } \\
\text { - Bond yield } \\
(\%)\end{array}$ \\
\hline \multicolumn{4}{|c|}{ Panel A: 1957-1973 } \\
\hline Mean & 11.79 & 7.07 & 4.73 \\
\hline St.Dev. & 1.16 & 1.68 & \\
\hline Correlation & \multicolumn{2}{|c|}{0.94} & \\
\hline \multicolumn{4}{|c|}{ Panel B: 1972-1993 } \\
\hline Mean & 14.09 & 11.54 & 2.56 \\
\hline St. Dev. & 1.68 & 2.10 & \\
\hline Correlation & \multicolumn{2}{|c|}{0.92} & \\
\hline \multicolumn{4}{|c|}{ Panel C: 1994-2009 } \\
\hline Mean & 8.04 & $5 \cdot 57$ & 2.47 \\
\hline St.Dev. & 1.76 & 1.46 & \\
\hline Correlation & \multirow{2}{*}{\multicolumn{2}{|c|}{0.95}} & \\
\hline \multicolumn{2}{|c|}{ Panel D: 1957-2009 } & & \\
\hline Mean & 11.57 & 8.37 & 3.20 \\
\hline St.Dev. & 2.98 & 3.21 & \\
\hline Correlation & & & \\
\hline
\end{tabular}

Table 2 presents descriptive statistics on the annual time series of average annuity rates and consol rates over the period 1957 to 2009 and for three sub-periods.

In addition to the gradual trend of a narrowing gap between annuity and consol rates, there is also a temporary narrowing of the gap in the mid 1970s when all interest rates were high. The likely reason for this is that when interest rates are high, the present value of future payments in the relatively distant future contribute very little to the total present value of an asset and most of the present value of the asset depends upon payments in the very near future. Since the probability of annuity payments in the near future is very high, the expected present value of the annuity payments for the near future is almost the same as the expected present value of a bond. Of course, this reasoning relies upon annuities being priced fairly, but all of the evidence we shall present below suggests that this is approximately the case. 


\subsection{Annuity rate data: Compulsory Purchase Life Annuities (Pension anuities)}

Having discussed the voluntary annuities market, in this section we focus on nominal and real compulsory purchase annuities, bought by individuals who have received tax-breaks in accumulating pension funds, and who must annuitize a proportion of that fund and purchase annuities in the compulsory purchase market where annuity rates are slightly better, possibly due to fewer selection effects as argued in Finkelstein and Poterba (2002).

We report data on quoted annuity rates provided by MoneyFacts over the period 1994-2007. Although the voluntary market data goes back to 1957, for much of that period the compulsory annuity market was very small and no data are available. In this section the data we use are quoted annuity rates for the compulsory annuity market provided by Moneyfacts from July 1994 to March 2009. As in the voluntary market we compute average annuity rates from the various annuity providers for both men and women of different ages. MoneyFacts provide annuity quotes for level annuities with no guarantee that pay a constant monthly income stream over the lifetime of the annuitant. MoneyFacts also publish RPI-linked annuities, which pay an annuity income that rises in line with the UK's Retail Price Index, and hence provides protection against inflation to the annuitant.

Cannon and Tonks (2004b) discuss potential problems with inferring an average annuity rate from a cross-section of annuity quotes in the voluntary market from a wide range of sources, because of changes due to composition bias. In our data set on the compulsory market, we have a consistent source of data and any changes in the number of prices available are due to changes in the number of actual providers: in most cases we can identify changes in the number of prices with merger or acquisition of one provider by another. Although prices of individual providers rarely change on a monthly basis, changes are sufficiently frequent that there is not reason to believe that any prices are stale. 
Figure 4

Annuity Rates in the Compulsory Annuity Market for Males

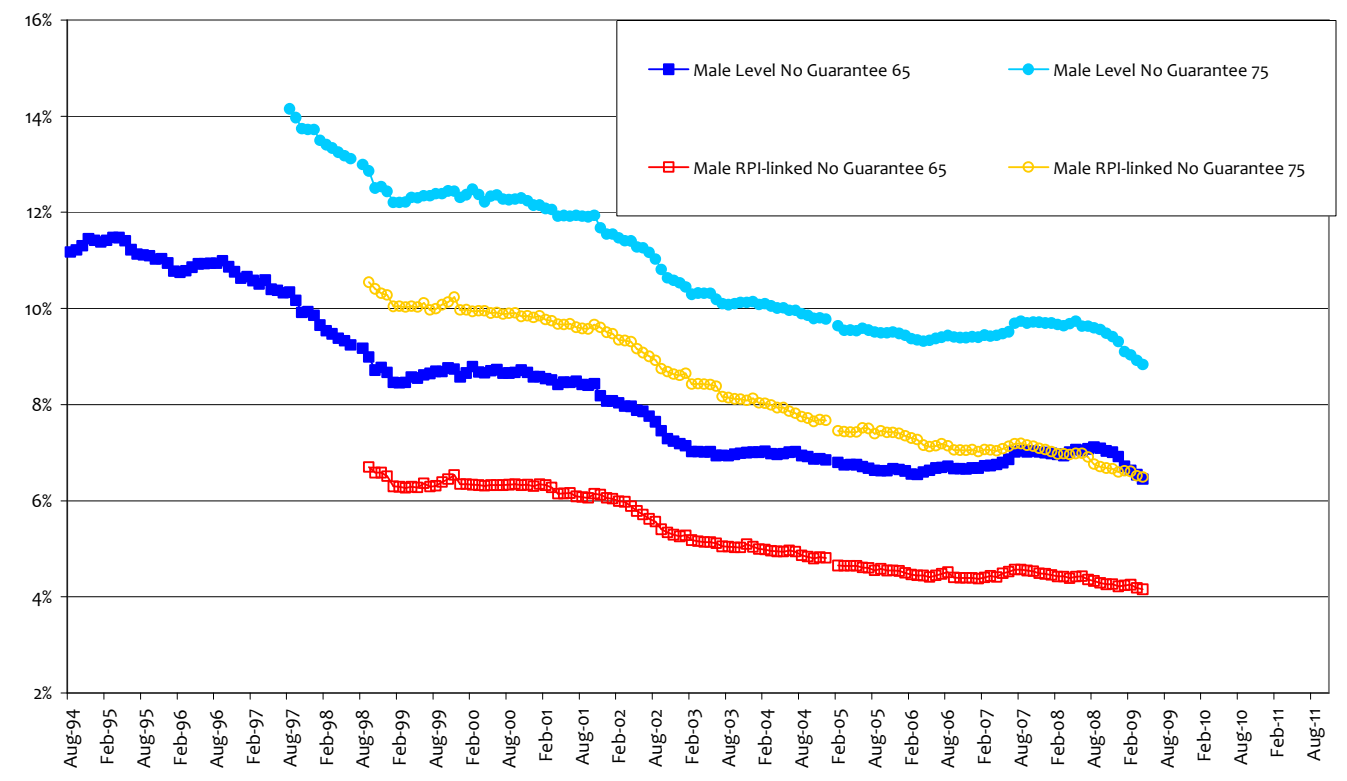


Figure 5

Annuity Rates in the Compulsory Annuity Market for Females

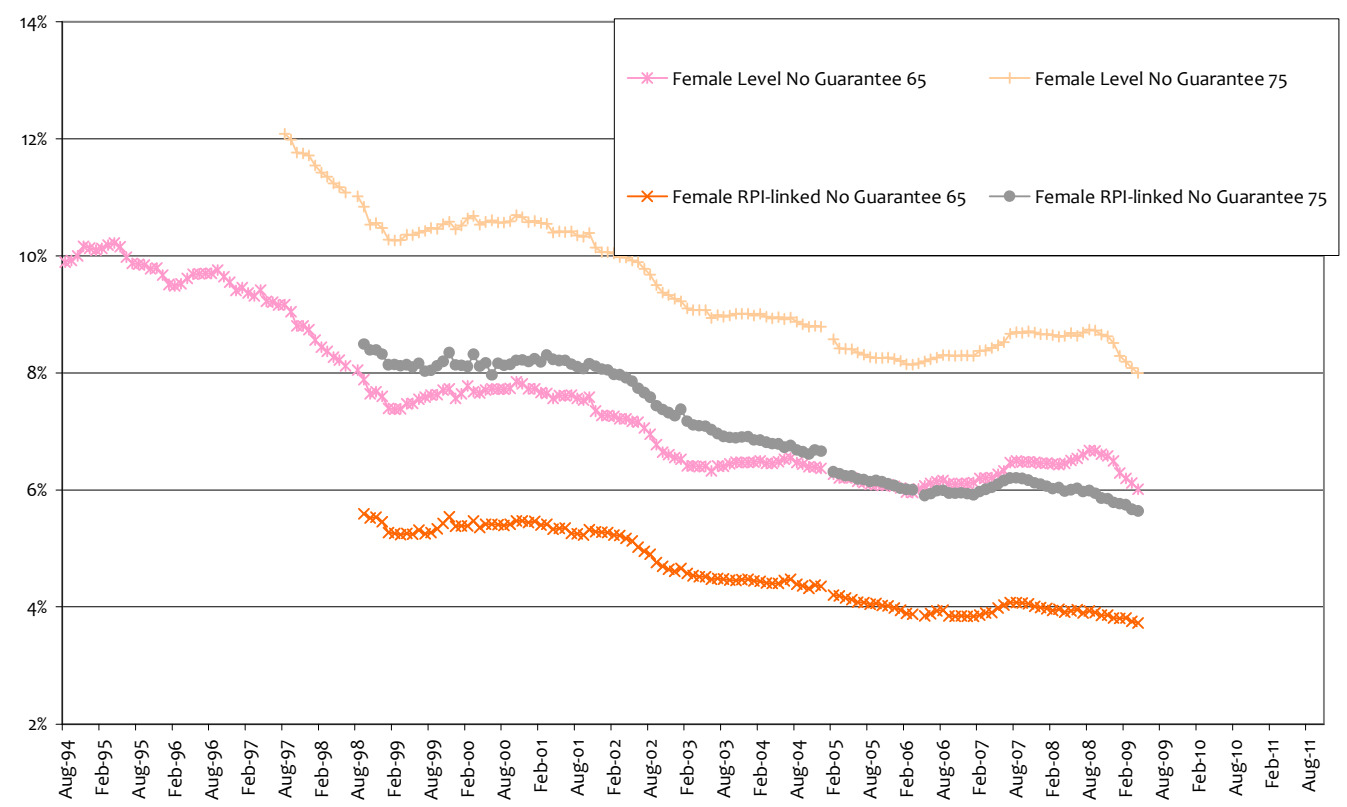

Figures 4 and 5 plots a series of monthly annuity rates for men and women aged 65 and 75 over the period (75-year olds annuity rates were only quoted in Money Facts from August 1997 and RPI-linked annuities were only quoted from September 1998 - in addition two months' data are missing). It can be seen that annuity prices move closely together, largely in line with interest rates.

As with the voluntary market annuity rates for men are consistently higher than for women of the same age; and that annuity rates are higher for both men and women as age increases. The annuity rates on guaranteed annuities always lie below non-guaranteed annuities, and the rates on index-linked annuities lie below those on nominal annuities. Like the voluntary market the striking aspect of Figures 4 and 5 is the extent to which the series move together.

Figure 6 reveals that the number of main annuity providers during this period has fallen significantly: in 1994 MoneyFacts reports 23 to 25 quotes, but this falls to about nine quotes by the end of the period. The FSA web-site also has also 
reported about nine or ten annuity prices over the period 2005 to 2007 . It should be noted that that some of the annuity providers only supply enhanced or similarly-restricted annuities, such as B\&CE Insurance which supplies annuities to former construction workers. The number of annuities quoted for this part of the market has actually grown (some of these are provided by companies that also provide non-enhanced annuities). Figure 6 also shows that not all annuity providers quote for RPI-linked annuities in Money Facts.

Figure 6

\section{Number of annuity quotes in Money Facts}

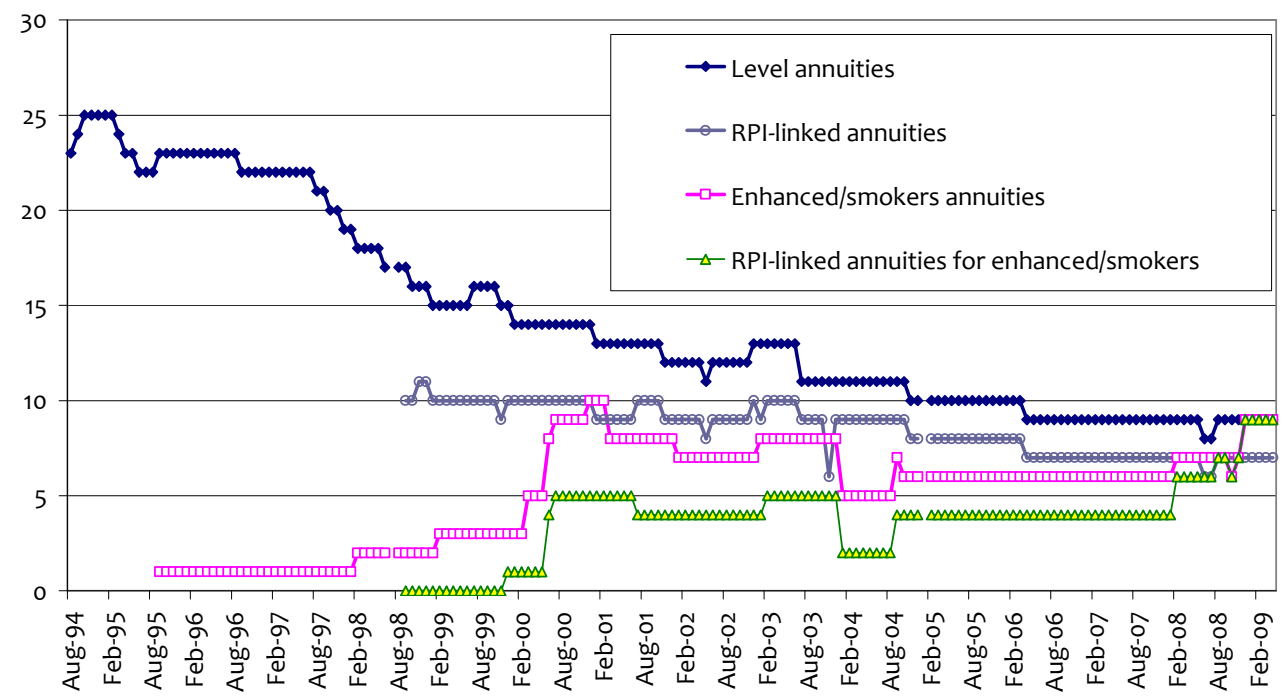

Although the number of annuity providers quoting annuity prices in the Moneyfacts database has fallen, insurance companies may still be willing to provide annuities if contacted directly by individuals or annuity brokers, for example they will sell annuities to those who have built up pension savings with the company. According to the FSA life insurance returns 62 insurance companies sold compulsory annuities in 2005 , and in Figure 7 we reproduce the distribution of non-profit compulsory annuity sales in 2005 across the largest 23 of the 39 parent companies that sold annuities (since a parent company may 
submit more than one insurance return for its subsidiary companies). ${ }^{6}$ These 23 companies sold $£ 7,398$ million of CPA non-profit annuities in 2005 out of a total of $£ 7,433$ million for this category. There were a small number of other categories of compulsory annuities sold in 2005: with-profit annuities (£229 million), RPI-linked ( $£ 510$ million), impaired-life ( $£ 387$ million), but these are not included in the figure.

Figure 7 shows that the CPA market is dominated by a small number of insurance companies, and the number in this figure imply that the five-firm concentration ratio is 72 per cent for these annuity sales, with the Prudential the largest supply of compulsory annuities having over 23 per cent of new business in $2005 .{ }^{7}$

The ten annuity providers identified as quoting annuity prices from the MoneyFacts database in August 2005, were AXA, Canada Life, Clerical Medical (HBOS), Friends Provident, Legal \& General, Norwich Union (Aviva), Prudential, Scottish Equitable (AEGON), Scottish Widows (Lloyds TSB), and Standard Life. By comparing these providers with the sales of annuities in 2005 from the FSA returns, it would appear that our dataset contains price quotes from all the major providers.

\footnotetext{
${ }^{6}$ Form 47, Synthesis Database

${ }^{7}$ The five-firm concentration ratio shows the percentage of total industry annuity sales contracted by the largest five annuity providers.
} 


\section{Figure 7:}

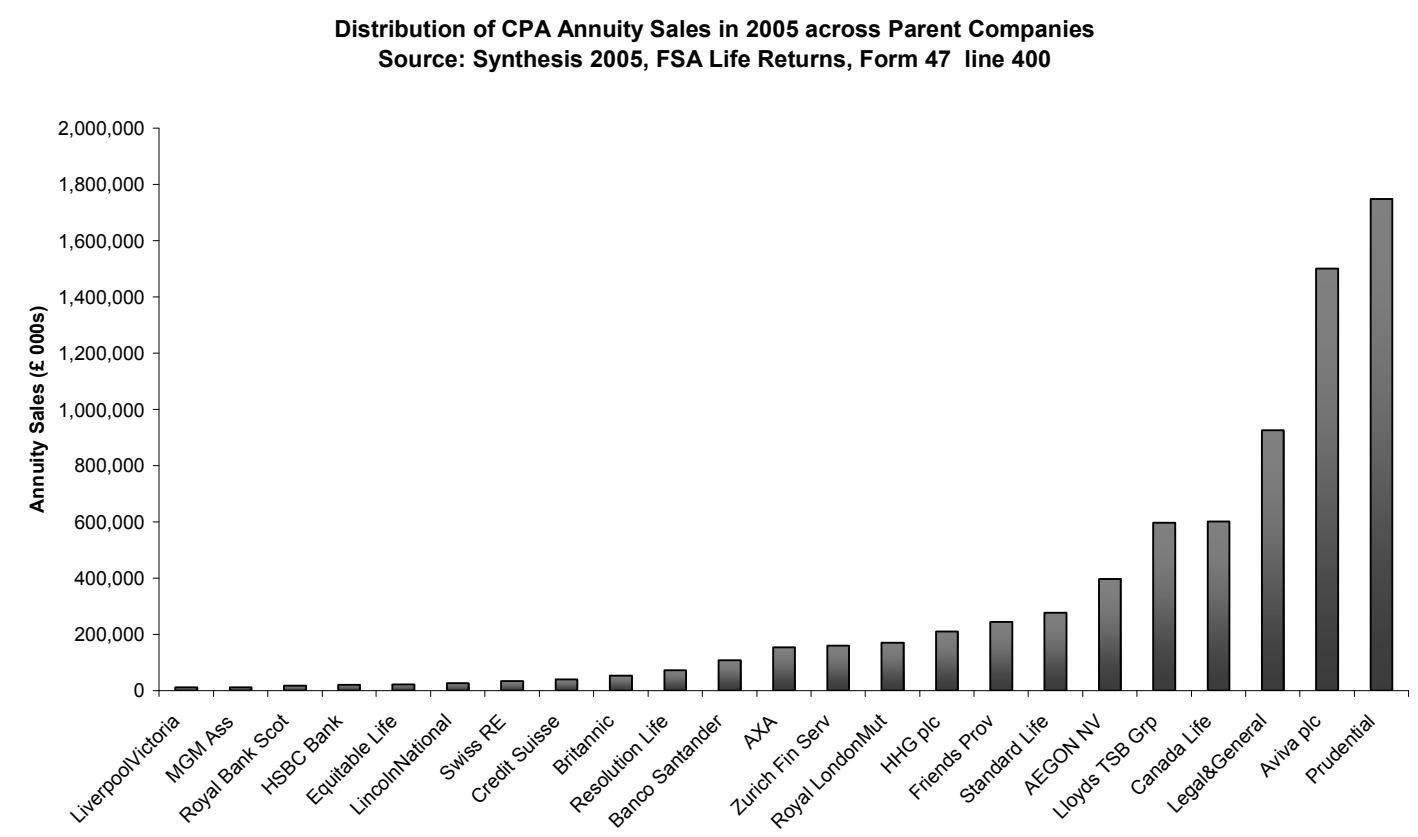

We may also examine the pattern in the concentration ratio over time. In Figure 8 we plot the six-firm concentration ratio from 1985-2005 of CPA sales. This figure is based on the CPA annuity sales of the individual company FSA returns, rather than aggregate sales across the parent companies. Ideally an analysis of market concentration would use data at parent company level, but insurance company mergers would make it very difficult to extract the parent information in a particular year and thus we confine our analysis to the individual companies. Because we are analysing individual companies Figure 8 may understate the true degree of concentration, but this effect is likely to be small. For example in 2005, Figure 8 reveals that the six-firm concentration ratio was 68 per cent (based on individual company returns) compared the fivefirm concentration value of 72 per cent (based on the parent company's returns) derived from Figure 7. 
Figure 8:

Six firm concentration ratio 1985-2005 in CPA Market

(Based on individual company FSA returns)

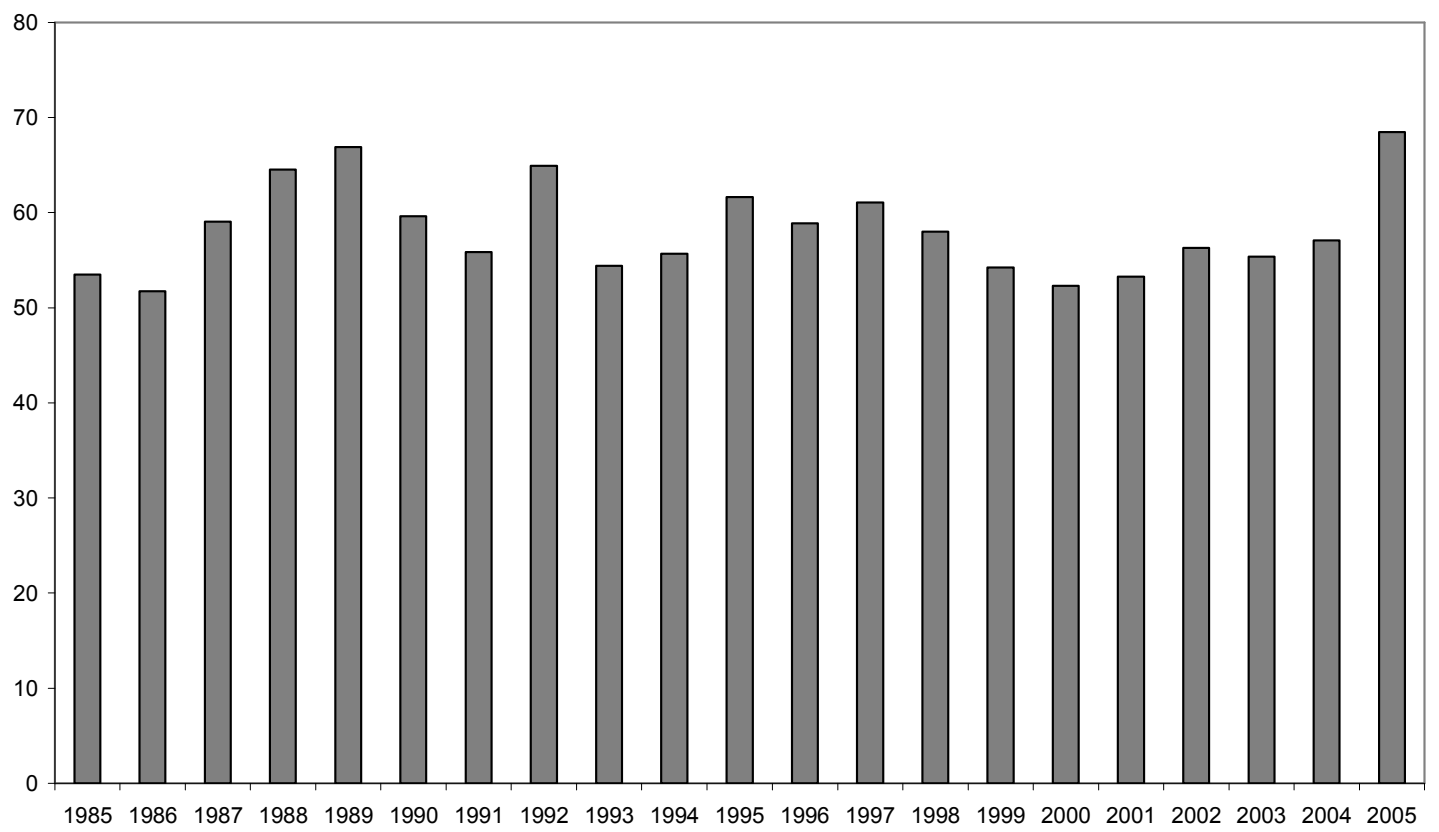

Source: Synthesis 2005

Figure 9 provides a comparison of annuity rates in the compulsory market with long-term interest rates. It compares the nominal annuity rate for 65 -year-old males with the UK government ten-year bond yield. It can be seen that the two series clearly move very closely together, although the annuity rate is slightly smoother. In addition figure 8 also plots the yield on corporate bonds yield. ${ }^{\text {iii }}$ The figure also plots the inflation-adjusted annuity rate in the real annuity market and the real government bond yield. 
Figure 9

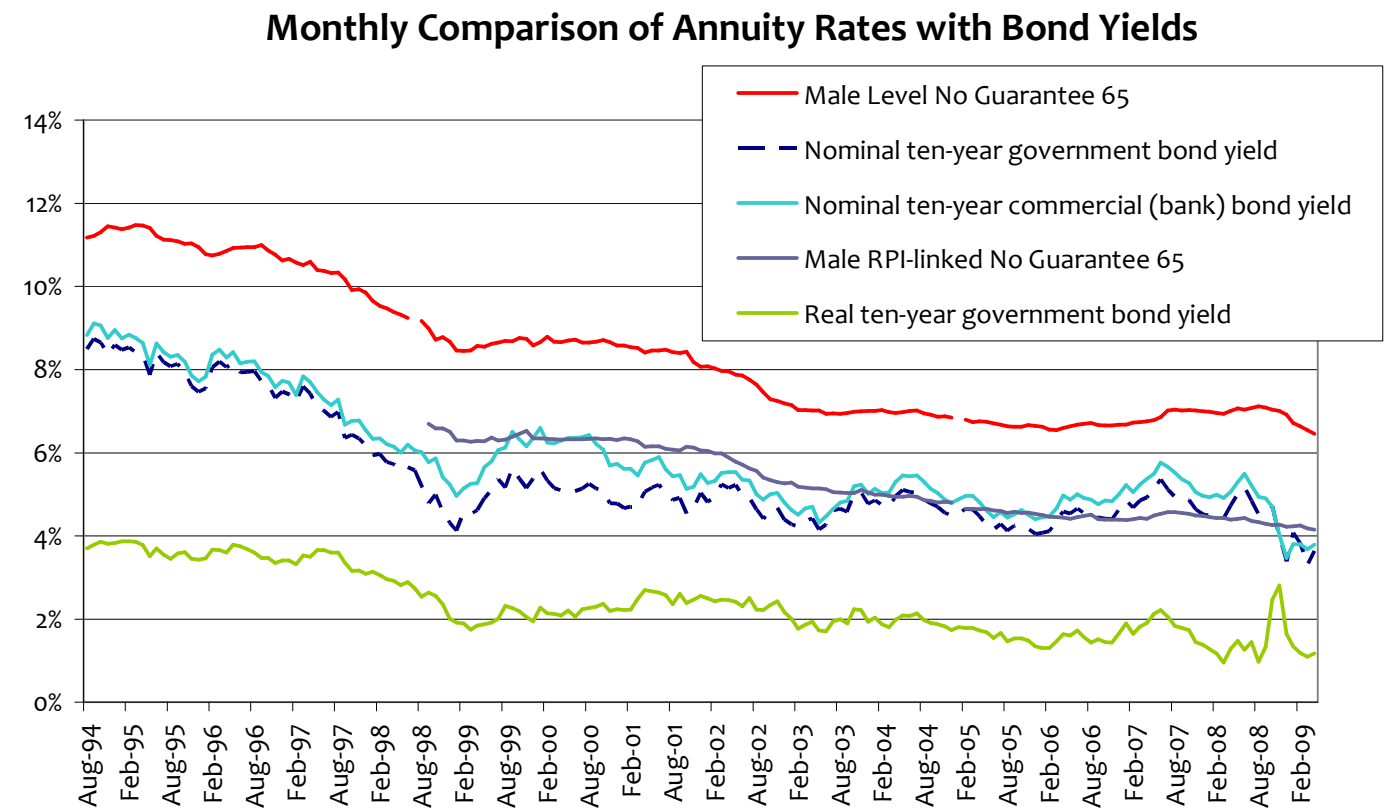

Descriptive statistics for pension annuity rates in the compulsory market and bond yields are presented in Table 3 for the period as a whole, and for two subperiods. As expected, the series are highly correlated, but this correlation has decreased from 0.97 in the late 1990 through to 2002 to 0.49 over the last seven years. The difference between the two series is falling over time because as life expectancy increases, the expected payment stream from an annuity becomes more similar to that of a conventional bond. The lower correlation over the latter part of the sample appears to be driven by the higher short-term volatility in bond yields: bond yields have become more volatile, but annuity yields have not responded to this volatility on a month-by-month basis. The annuity rate was 9.9 per cent between $1994-2000$, but had fallen to 7.2 per cent over the second half of the dataset for 2001-2007. Table 3 also reports the yields on corporate bonds, and this has averaged about 90 basis points above the yield on government bonds ${ }^{8}$. Using the corporate bond rate as the appropriate discount rate, or including the risk premium on corporate bonds, will therefore reduce the present value of annuity payments, and hence reduce the money's worth. 
Table 3: Monthly Time Series Properties on Pension Annuity for 65-year old males and 1o-year Bond Rates

\begin{tabular}{|c|c|c|c|c|}
\hline & $\begin{array}{l}\text { Annuity Rate } \\
\text { for } 65 \text {-year } \\
\text { old males } \\
(\%)\end{array}$ & $\begin{array}{c}10 \text { year } \\
\text { Government } \\
\text { Bond Yield } \\
(\%)\end{array}$ & $\begin{array}{c}\text { Commercial } \\
\text { Bank Bond } \\
\text { Yield (\%) }\end{array}$ & $\begin{array}{c}\text { Difference } \\
\text { (\%) in } \\
\text { Annuity Rate } \\
\text { and } \\
\text { Government } \\
\text { Bond Yield }\end{array}$ \\
\hline \multicolumn{5}{|c|}{ Panel A: Aug 1994-Jan 2002} \\
\hline Mean & 9.67 & 6.27 & 6.83 & 3.41 \\
\hline St.Dev. & 1.15 & 1.43 & 1.20 & \\
\hline Correlation & \multicolumn{2}{|c|}{0.97} & & \\
\hline \multicolumn{5}{|c|}{ Panel B: Feb 2002 - Apr 2009} \\
\hline Mean & 6.96 & $4 \cdot 58$ & $4 \cdot 91$ & 2.38 \\
\hline St. Dev. & 0.34 & 0.39 & 0.45 & \\
\hline Correlation & \multicolumn{2}{|c|}{0.49} & & \\
\hline \multicolumn{5}{|c|}{ Panel C: Aug 1994 - Apr 2009} \\
\hline Mean & 8.33 & $5 \cdot 43$ & 5.88 & 2.90 \\
\hline St. Dev. & 1.60 & 1.35 & 1.32 & \\
\hline Correlation & \multicolumn{2}{|c|}{0.92} & & \\
\hline
\end{tabular}

Table 2 presents descriptive statistics on the monthly time series of average annuity rates in the CPA market, government rates and commercial bond rates over the period 1994 to 2009 and for the two sub-periods.

\subsection{Interest rates and the term structure}

The term structure of interest rates is available on a detailed basis on the Bank of England's web site. The Monetary Instruments and Markets Division of the Bank of England estimates nominal and real yield curves for the United Kingdom on a daily basis. These estimates are based on yields on UK government bonds and on yields in the general collateral repo market. They are constructed by fitting a smooth curve through data points for rates of return on government stock of different maturities, as described in Anderson and Sleath (1999). However the current published series were only calculated from 1999 and so these estimates would not have been available in this form to insurance

\footnotetext{
${ }^{8}$ We use the Datastream corporate bond index rather than the Merrill Lynch index, since the two series are highly correlated, but the Merrill series only started in 1997.
} 
companies pricing annuities contemporaneously between 1994-1999. Up to 1999, published yield curve data was available in Financial Statistics for representative government bonds at 5, 10 and 20 years, and it would have been possible to infer rates of return on intermediate maturities by interpolation or on longer maturities by extrapolation. In Cannon and Tonks (2004a) we compared the current Bank of England term structure series for 1979-2002 with the interpolated series, and found that the results were very similar. Therefore in the current analysis we will rely solely on the Bank of England term structure series for 1994-2007.

What are the implications of the shape of the term structure for the pricing of annuities? Consider the optimal investment strategy for the annuity provider: to meet future liabilities a long way into the future the life insurer can either a) make a single purchase of an asset making a payment at that point in the (longdistant) future: when the payment is received then the funds are automatically available to meet the life insurer's liability to make the annuity payment; or b) invest money short term and continuously re-invest it until it is needed for the annuity payment.

Historically, most of the time the yield curve has sloped up: the interest rate per annum for payments a long way in the future is higher than for those in the near future. This means that the obvious strategy for a life insurer selling an annuity is to match annuity payment liabilities that are a long way in the future with financial products making payments a long way in the future. There are three advantages to this approach. First, buying long-dated assets has a higher rate of return. Second, it involves less administrative costs, since only one transaction is needed rather than continuous transactions as short-term investments are rolled over. Third, there is no risk, since the payment in the future from a government bond is certain (government default risk is clearly negligible in the UK), while investing short term and rolling over the investment is risky as short-term rates of return are variable. Given these advantages the FSA strongly encourages life insurers to match their annuity 
liabilities with an appropriate mix of assets with differing maturities and the life insurers are obliged to provide details of their asset portfolio in the FSA returns, which show that they do behave in this way.

For this reason it is appropriate to use the rates of return from the term structure to obtain the present value of annuity obligations. One slight problem arises, however, when the yield curve slopes down (ie long-term interest rates are less than short-term interest rates) as has been the case in the UK recently. In this situation investing short term and rolling over the investment has a higher expected return on average; but this is at the expense of there being higher risk. If this risk were sufficiently low then it might be optimal for life insurers to invest short term and it would not be appropriate for us to value annuity liabilities using the term structure.

However, we believe it more appropriate to continue to use interest rates drawn from the term structure even in this situation. First, data limitations mean that there is little alternative: clearly there is no independent source of information on future short-term interest rates or the value of risk in investing short term and rolling over investments rather than investing long term (indeed, the obvious way to estimate these values would be to use the term structure, which brings us back to where we started). Second, it is not clear that life insurers have used such a strategy, or that the regulator would allow them to do so.

We will use term structure projections in the computation of money's worth in Section III. Form 49 of the FSA insurance returns provides information on the types of bonds in which life insurance companies invest. Figure 9 shows that the mixture of government bonds (approved) and corporate bonds (other) has shifted over time: in 1985 life insurance companies held five times as many government bonds as corporates, by 2005 this ratio was almost one, though over most of the sample, 1989 to 2004, the percentage of debt instruments that were government bonds lay between 60 and 70 per cent. 
Figure 9:

Type of Debt Instrument held by Life Insurance Companies

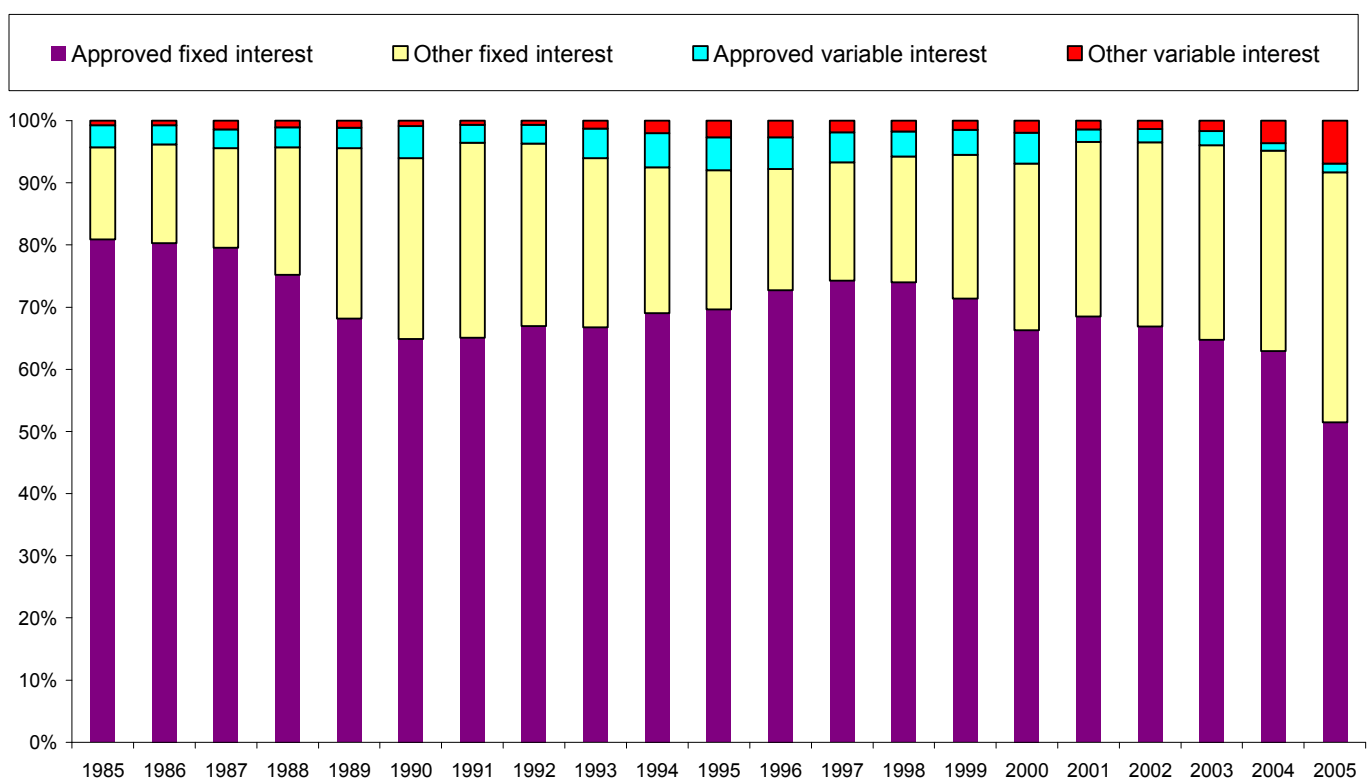

Source: Synthesis, 2005

\subsection{Life expectancy}

We now turn to the behaviour of life expectancy over the period 1994 to 2009. Clearly annuities are (or should be) priced on future life expectancy, so we are dealing with past values of expectations about the then future (much of which is still in the future). Cannon and Tonks (2008) discuss many of the issues in working out what expectations of mortality might have been in the past, using the actuarial tables that were available at various points from 1950 onwards. The period in which we are interested saw some major revisions to actuarial projections and this means that changes in expectations are the largest cause of changes in annuity rates over this period.

Two initial issues that we need to consider are the fact that annuitants may have different life expectancy from other individuals, and voluntary annuitants may have different life expectancy from pension annuitants. The life expectancy of pensioners is quite different from that of the population as a whole, and there is also considerable variation in life expectancy between the 
different sorts of pensioners for which data are available. A large quantity of data is collected by the Institute of Actuaries and analysed by the Continuous Mortality Investigation (CMI) Committee which publishes its results at regular intervals, typically publishing the data for four-year periods ("quadrennia”). We follow Finkelstein and Poterba (2002) and our own analysis in Cannon and Tonks (2004a) in using the CMI data. The CMI collects data for individuals with the following types of pension:

1. Immediate annuities, which would be appropriate for the analysis of annuities purchased voluntarily in the "purchase life" market;

2. Retirement annuity contracts (RACs), an early version of personal pension introduced in 1957 primarily designed for self-employed workers to have a mechanism to receive the tax privileges available to workers in company pension schemes;

3. Personal Pensions (PP), introduced in 1987 and for which the data set is small until about 1995, since most such pensions are still in accrual rather than in payment;

4. Life office pensions, which are company pension schemes administered by life insurers and for which the most comprehensive data are available;

5. Self-Administered Pension schemes, ie, company pension schemes, typically for large companies, which are run by the company without recourse to life offices (although they would be advised by actuarial consultancy firms). ${ }^{9}$ The CMI has started collecting these data only very recently and hardly any data are available.

Summary statistics of some of these data are shown in Table 4, which illustrates the small size of the voluntary annuity market, the relatively large size of the RAC market and the phenomenal growth of the PP market. The Table shows the number of annuitants by annuity-type over various quadrennia, and the associated death rates for each group.

\footnotetext{
${ }^{9}$ Self-Administered Pension schemes (SAPs) are those self administered by the company and should not be confused with Self-Invested Personal Pensions (SIPPs) which are a form of personal pension, where investment decisions are taken by the pensioner.
} 
Table 4: CMI Estimates of numbers of annuitants and death rates by categories of annuity

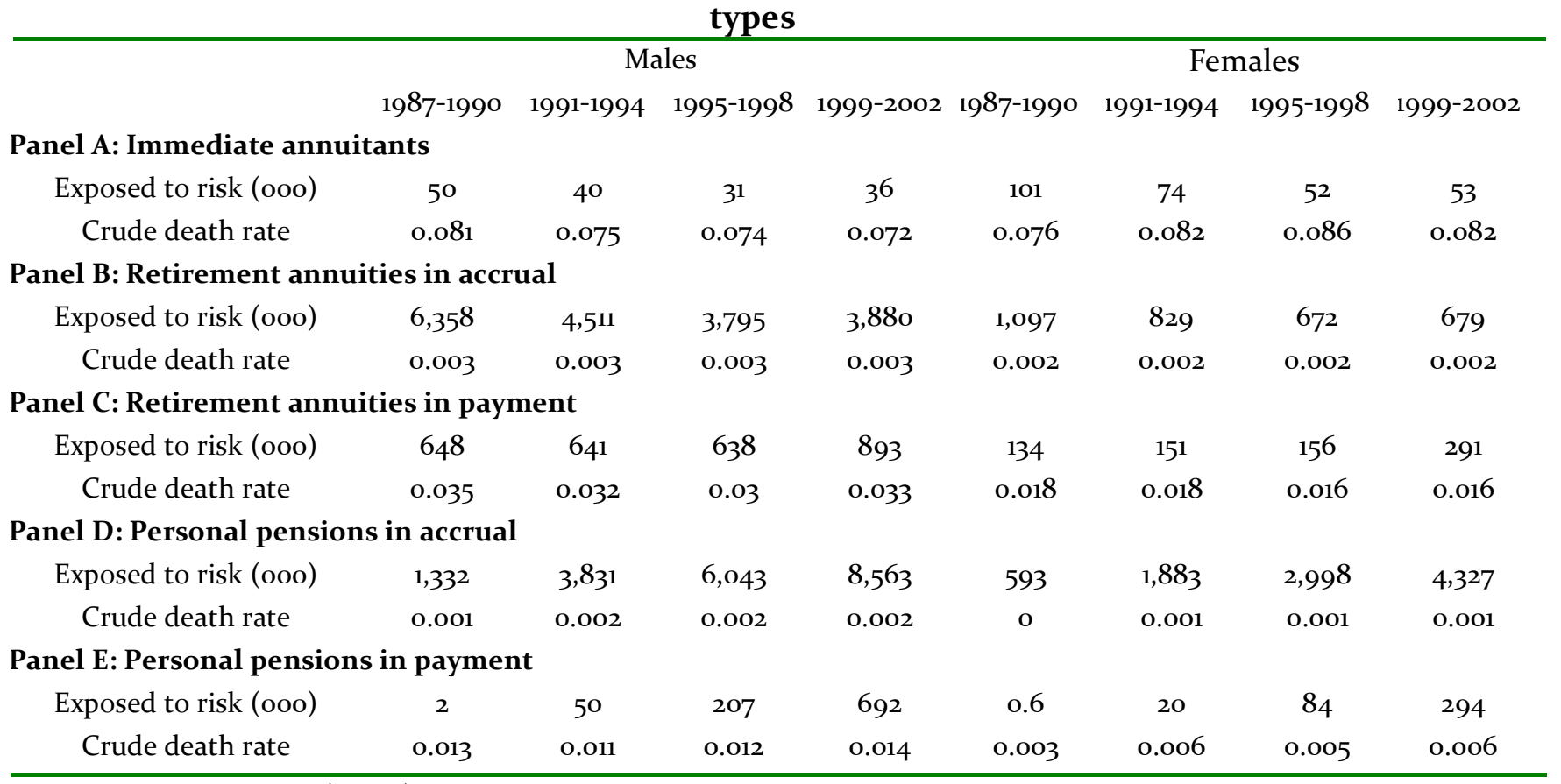

Source: CMI 21 (2004)

Clearly in an ideal world we would use immediate annuitant life expectancy data for the voluntary annuities, and the Personal Pensions life expectancy data for pension annuities, since most people who purchase annuities in the compulsory-purchase market are classified as Personal Pensioners by the CMI, since we would like to ensure consistency in the data. However, as can be seen from Panel $\mathrm{E}$ in the table, it is only recently that significant numbers of individuals with personal pensions have been monitored by the CMI and so these data alone could not be used reliably for projection into the future. Furthermore they were first published only in 2004 (although a smaller sample had been available before then) and so were unavailable for most of the period.

An alternative would be to use the RAC life expectancy for pension annuities, but Panel $C$ in Table 4 above suggests that the death rate of such pensioners is twice as high as the death rate of personal pensioners (looking at pensions in payment rather than in accrual) and hence the life expectancy is much lower. 
In fact these summary statistics exaggerate the difference since the average age of RAC pensioners is higher than PP pensioners, but differences remain even when we disaggregate the data by age. This difference in life expectancy may be because the two groups have different socio-economic characteristics. A possible explanation is that originally purchasers of RACs were self-employed and thus they may have different characteristics from people in employment: certainly they are likely to have worked in different occupations and this may explain some difference in life expectancy (some occupations have significantly different life expectancies from others: eg construction workers tend to have lower life expectancy).

Since the number of RAC pensioners in accrual has fallen by 7.5 to 4.6 million over the period, coinciding with an increase of PP pensioners in accrual from 1.9 to 12.9 million, it is almost certain that some individuals who would have taken up RACs are now taking up PPs (as we would have expected) and this would suggest that their life expectancies would be similar. However, there have also been changes in the composition of the workforce and this effect may be larger.

Given the problems with interpreting RAC and PP life expectancy it seems prudent to follow Finkelstein and Poterba (2002) and resort to a larger and more consistent set of data, namely the Life Office Pensioners, of whom there were over one million in 1999-2002 and for whom data are available for a longer period of time. Use of the Life Office Pensioner data has the additional advantage that life expectancy is available on both a lives and an amounts basis. ${ }^{10}$ The former shows the life expectancy of each life (possibly more accurately of each policy - if a pensioner has more than one policy then he or she may be counted twice). The latter basis re-weights the life expectancy by

\footnotetext{
${ }^{10}$ In the Results section we will refer to PML (Pensioner Male Lives) as Life Office Pensioner data for males based on lives. Similarly, PFA (Pensioner Female Amounts) refers to Life Office Pensioner data for females based on amounts. The most recent life expectancy tables also refer to PNML (Pensioner Male Normal Lives) to distinguish between those people retiring at normal retirement age as distinct from early retirees.
} 
the size of the pension so that richer pensioners have a higher weight unsurprisingly life expectancy of amounts is longer than life expectancy of lives since richer people tend to live longer. From the point of view of the Life Office, what matters is the amounts measure, since that is what determines the profitability of the life business: from the point of view of a "typical" pensioner the lives basis may be more relevant in terms of the "value for money" of the annuity.

We now turn to the way in which actuaries have projected life expectancy over the relevant period. Since their projection methods have changed, this will involve a summary history of actuarial thinking. It is not possible to identify how actuaries in specific insurance companies made their projections in the past, but we can consult the CMI reports as a "best practice" guide. At discrete intervals the CMI produces "standard tables" usually through the medium of a CMI Report, accompanied by a software package for calculating certain functions based on the mortality data. Recently the CMI has started producing Working Papers to supplement the Reports, partly so that information can be disseminated in a more timely manner (since Working Papers contain provisional results). In addition to this Reports have a semi-official status: for example, they are recognised by the regulatory authorities. Since Working Papers do not have any official status they are a means of promoting discussion within the actuarial profession while avoiding any obligation on actuaries to utilize results which are only provisional. The relevant tables for the subperiods in our sample are described in Table 5.

Table 5: Data used by Continuous Mortality Investigation Committee of the actuarial professional organizations in the UK to calculate life tables

Table

$\mathrm{a}(55)$
Publication

Publication

Date

1953
Based on data up to year 1948

\footnotetext{
${ }^{11}$ However, we cannot assume that an individual with lower life expectancy than average will necessarily get less additional utility from purchasing an annuity (based on average life expectancy) than an individual with higher life expectancy. We discuss this below.
} 


\begin{tabular}{lccc}
\hline $\mathrm{a}(90)$ & CMIR 3 & 1978 & 1974 \\
80 Table & CMIR 10 & 1990 & 1982 \\
92 Table & CMIR 17 & 1999 & 1994 \\
$\begin{array}{l}92 \text { Table interim adjustments } \\
\text { (with short, medium and long } \\
\text { cohort assumptions) }\end{array}$ & CMI WP 1 & 2002 & 1999 \\
oo Table & CMIR WP 22 & 2006 & 2002 \\
\hline
\end{tabular}

Three different methodologies were used in the actuarial tables identified in Table 5, and we now describe these in turn. In all cases the actuarial methodology relies upon the "mortality", or probability of dying at a given point of time for someone of a given age (males and females are always treated separately). Since the probability of dying at age 62 is very similar to the probability of dying at age 61 , it seems reasonable to fit a smooth curve to the data (called a "graduation"), which summarises the mortality-age relationship and smoothes out idiosyncratic variations in the observed death rates. Differences in methodology depend primarily on the method of curve-fitting and how this is projected into the future. Once we have suitable mortality projections, it is possible to calculate the probability of the annuitant receiving each annuity payment and hence the money's worth of the annuity. To illustrate this, suppose we treat the data in discrete annual terms, and write $m(x, t)$ as the probability of dying (mortality) in year $t$ of a person aged $x$. Then the probability of being alive in year $t+s$ is

$$
\prod_{i=0}^{i=s-1}\{1-m(x+i, t+i)\}
$$

and the expected value of an annuity paying $£ 1$ per year is

$$
\sum_{s=1}^{s=\infty} \delta(s)\left[\prod_{i=0}^{i=s-1}\{1-m(x+i, t+i)\}\right]
$$

where $\delta(s)$ is the net present value of $£ 1 s$ years hence. 
Consider the mortality data available at some point in time, for example in 1995. If data were available up to 1994, then data would be available up to 1994 for all ages. To calculate the value of an annuity for a man aged 65 in 1995 it would be necessary to predict the mortality for a 65-year old in 1995, a 66-year old in 1996, a 67-year old in 1997 and so on. The way that the 8o and 92 Actuarial Tables would have done this is as follows: they would start by fitting a curve to mortality data for a particular year: for example in 1992 (which indeed is the base year in the 92 Tables, hence their name). By looking at the trends of mortality for up to 1994, it would make predictions for the curve for years 1995 and onwards and hence extract the relevant mortalities that would be needed.

The 80 tables used 1980 as the base year and then projected mortality rates forward using a formulae such that the mortality at a given age in a given year was the 1980 mortality reduced by a "reduction factor". This reduction factor consists of two parts: a component determines the "limiting" reduction, ie how much the mortality is assumed to fall by in the indefinite future; and a second component determining how quickly the mortality is assumed to move from the 1980 value to the limiting value. The speed of adjustment was independent of age in the 80 tables; but in the 92 tables both functions were made age dependent. Both of these tables viewed mortality as being based on age and time. An alternative viewpoint is that mortality would depend upon age and cohort of birth. For example, the base year graduation of 1992 used data on both 6o-year olds in 1992 and 70-year olds in 1992: people born in 1932 and 1922 respectively. If mortality improvements were a smooth continuous process then the use of age and time instead of age and cohort would make no difference. However, towards the end of the 1990 os evidence began to appear suggesting that the mortality experience of people born before 1926 was markedly different from people born after 1926, a phenomenon which was first highlighted by Willets (1999). In other words there was a discontinuity in the improvement of mortality and hence using age-time would result in different projections from using age-cohort. 
To see why this matters, suppose, for the sake of argument, that people born after 1926 had substantially lower mortality than people born before. ${ }^{12}$ In 1992 people aged 66 and younger belonged to the lower mortality cohorts and people aged 67 and over to the higher mortality cohorts. The 80 and 92 tables would make mortality projections based on people born pre-1926, so mortality projections for a 65-year old man buying an annuity in 1995 would be based on post-1926 individuals' cohorts only for years 1995 and 1996 and thereafter on people born pre-1926.

Of course, one of the biggest problems in making such projections is the fact that when the 92 tables were produced there was hardly any information at all on the mortality of people born after 1926 during the later part of their lives. However, the CMI did have access to the mortality of such people in the earlier part of their lives, not from annuity data, but from life assurance data. Using the Male mortality life insurance data (based on lives rather than amounts), revisions were made to the 92 tables which were published in 2002 and called the "interim adjustments". ${ }^{3}$ The size of the revision depended upon the size and dating of the cohort effect and this cohort effect was difficult to estimate precisely on the data available. Accordingly three different assumptions were made and three corresponding sets of revisions produced, called respectively the "short", "medium" and "long" cohort assumptions. The difference between these three assumptions is the point at which they assume that the improvement in mortality ceases to be relevant. The short cohort projections assume that the mortality improvements observed in the post-1926 cohort cease to occur after 2010: the medium cohort projections assume 2020 and the long cohort projections assume 2040. The differences between the medium cohort and long cohort are sufficiently far in the future that they make relatively little difference for immediate annuities (obviously they have much larger impacts

\footnotetext{
${ }^{12}$ Clearly every cohort has tended to show an improvement in mortality compared with the previous cohorts: someone born in 1925 tends to have lower mortality compared with someone born in 1924 and someone born in 1928 has lower mortality compared with someone born in 1927. The suggestion being made here is that the difference between the 1925 and 1926 cohorts was much larger.
} 
for pensions still in accrual) and in our money's worth calculations below we concentrate just on the short and long cohort projections.

To give some idea of the magnitude of the changes due to revisions to the Actuarial Tables, the life expectancy of a 65-year old man (based on the projected mortalities) are illustrated in the Figure 10, based on the PML80 and PML92 Tables, and PML92 with the interim adjustments. Life expectancy of a 65-year old man was little more than 15 years in the mid 1990 os and predicted to rise only slowly: shortly after 200 this had been revised upwards to about 22 years, a huge change. Also for comparison we show the life expectancy based on the personal pensioner males (PPMoo) tables, based on the 2000 base tables and projected forward using the long cohort reduction factors, which suggest that personal pensioners have higher life expectancy than the life office pensioners.

\footnotetext{
${ }^{13}$ In producing these adjustments, the actuaries also used population data supplied by GAD.
} 
Figure 10

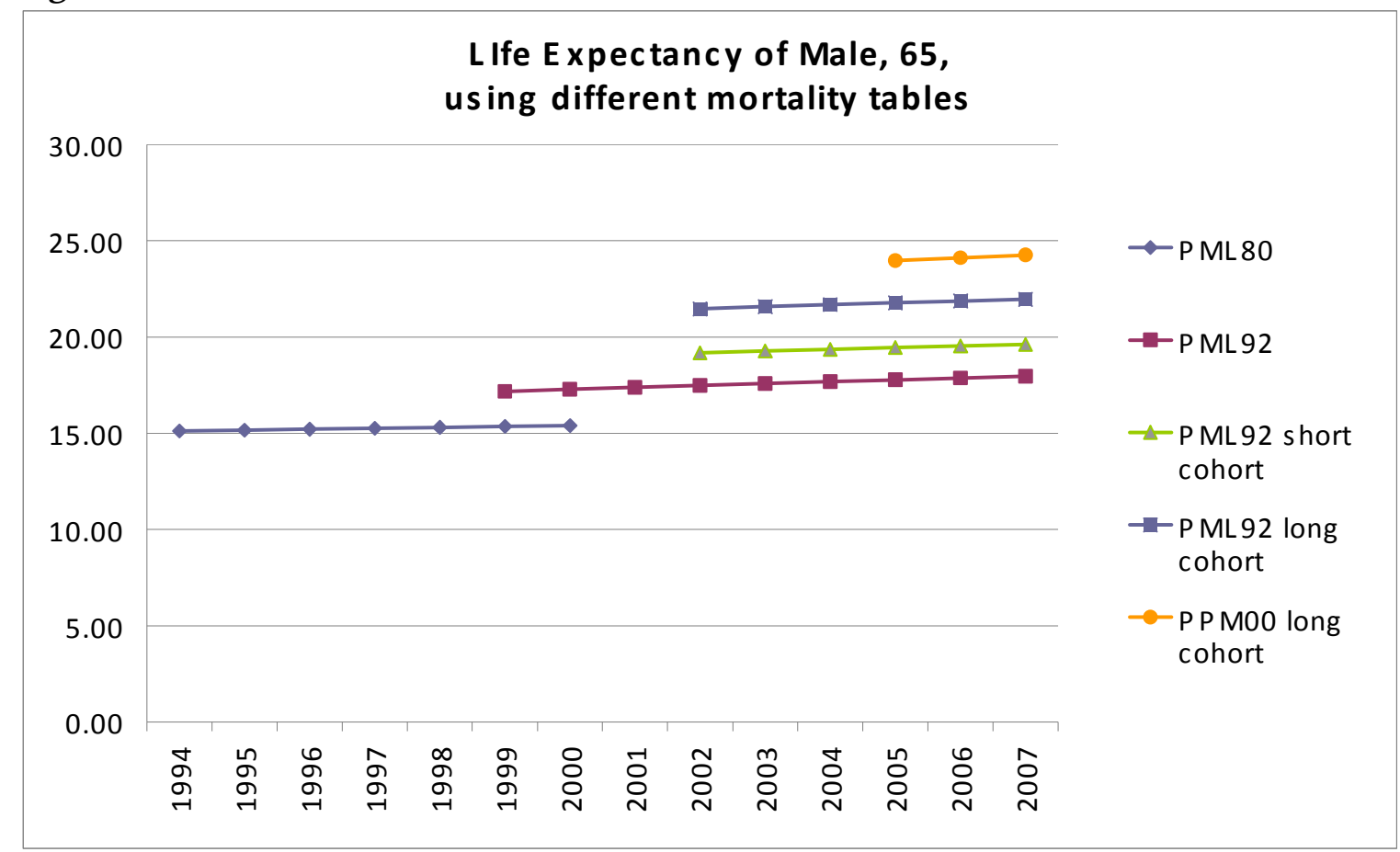

PML8o refers to Pensioner Male Lives from the 8o Tables, PML92 Pensioner Male Lives from the 92 Tables, Pensioner Male Lives from the 92 Tables with short and long cohort interim adjustments, and Personal Pensioner Males from the oo Tables using a long cohort interim adjustment

Alongside the concerns raised by the possibility of substantial cohort effects, actuaries have become increasingly concerned with the idea of making deterministic projections of mortality into the future, and have developed more sophisticated projection techniques, allowing for uncertainty in projections. One immediate consequence of this was that the oo Tables, unlike the 80 and 92 Tables, did not contain any suggested projections into the future at all. Instead, two complementary methods began to be employed to provide projections of mortality into the future, called p-spline and Lee-Carter. The previous tables had used data to fit a curve to a cross-section of mortality experiences, implicitly a two-dimensional relationship. The newer methods fitted a three-dimensional surface to the entire data that existed up to that point in time and then projected this surface into the future with appropriate statistical confidence intervals to provide a guide to the uncertainty of the estimates. These methods are discussed in more detail in Cannon and Tonks (2008). 
CMI Working Paper 20 considers the effects of incorporating these p-spline methods of projection, and computes the likely impact on annuity rates of using these newer methods relative to the previous methods. They find that using the p-spline methodology leads to much lower central estimates of the appropriate annuity rate for Males (although not Females). The key point, however, is that the 95 per cent confidence interval for the annuity rate based on the p-spline methodology is lower - for Males considerably lower - than that suggested by the Medium Cohort projections. The implication of this for our money's worth calculations is that by moving from one methodology to another could reduce the apparent money's worth by as much as 12 percentage points. We should be aware of this caveat when interpreting our money's worth results

\section{MONEY'S WORTH RESULTS}

The results on the money's worth calculations over various sub-periods of the data sample are presented in Tables 6- and Figures 11-. The general evidence is that money's worth for both voluntary and compulsory markets is just less than unity, though in some periods

\subsection{Money's worth of voluntary annuities}

Cannon and Tonks' (2004a) estimates of the money's worth for 65-year old males over the period 1957-2002 are reproduced in Table 6 and Figure 11, and this data has been updated to include the more recent evidence in the 20022009 purchased life annuity quotes. The money's worth is computed over different sub-samples, depending on the relevant actuarial tables, and in all cases the money's worth is very close to unity, implying that annuities were sold at a rate which was approximately fair in actuarial terms. The annuity quote data over the period 1957-1973 was obtained for 5-year guaranteed annuities, whereas post-1972 the quote data related to annuities without any guarantees. To obtain a single statistic on the money's worth over the sample 1957-2009 it is necessary to splice together the guaranteed and non-guaranteed 
annuity series. We estimate that over the whole sample 1957-2009 the average money's worth has been 0.983 , which is not significantly different from unity, and constitutes surprisingly high value for money. Though we note that over the recent years, money's worth of voluntary annuities has fallen to below 0.90. These money's worth calculations are based on annuity rates which are themselves a simple average of different companies' prices: the money's worth for the companies quoting the highest rates would have been very good indeed.

Table 6: Money's Worth of UK Annuities, Male, Lives, aged 65

\begin{tabular}{llccc}
\hline Years & Type of Annuity & $\begin{array}{c}\text { Actuarial } \\
\text { Table }\end{array}$ & $\begin{array}{c}\text { Mean } \\
\text { MW }\end{array}$ & p-value \\
\hline $1957-1973$ & no g'tee & $\mathrm{a}(55)$ & 1.034 & 0.078 \\
$1972-1980$ & 5-year g'tee & $\mathrm{a}(55)$ & 1.004 & 0.894 \\
$1978-1991$ & 5-year g'tee & a(90) & 0.978 & 0.057 \\
$1990-1999$ & 5-year g'tee & IM80 & 0.985 & 0.296 \\
$1999-2002$ & 5-year g'tee & IML92 & 0.938 & $0.023^{*}$ \\
$2001-2007$ & No g'tee & IML92 & 0.928 & 0.072 \\
& & long cohort & & $?$ \\
$2005-2009$ & No g'tee & IMLoo & 0.859 & $?$ \\
& & long cohort & & $?$ \\
\hline $1957-2009$ & No g'tee spliced & various & 0.983 & \\
& with 5-year g'tee & & & \\
\hline
\end{tabular}

Table computes the money's worth over different sub-samples of the dataset. The p-value reports a two-tailed t-test for whether the average money's worth is significantly different from unity. * denotes significance at the $5 \%$. p-values are robust to serial correlation..

Source: Cannon and Tonks (2004a) updated and revised 
Figure 11

\section{Money's Worth (Male 65) UK Voluntary Purchase}

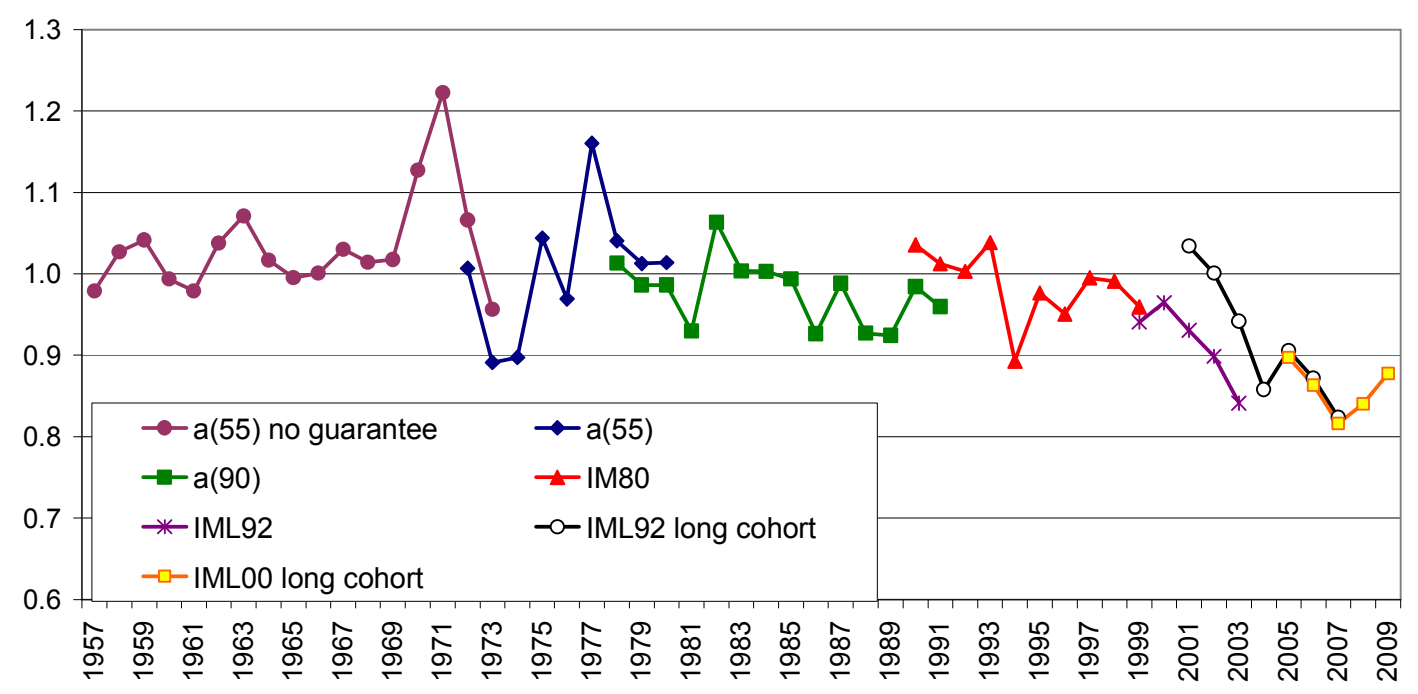

\subsection{Money's worth of pension annuities (compulsory purchase)}

We now turn to the money's worth of pension annuities in the compulsory purchase market. We will spend more time discussing these results, as we explained in Section 4 the data for the CPA market over the period 1994-2009 is from a single data supplier, and also as we know from the evidence in Figure 1, this market is much larger and more important than the voluntary market.

We first provide a comparison of money's worth based on mortality of male lives, in Table 7 and Figure 12 using the contemporary actuarial tables discussed above. Since it is impossible to date the precise point at which one should move from one life table to another we allow overlap years. The main feature of this graph is one which we shall find in the other graphs too: although the money's worth is close to unity, for any given life table, money's worth appears to be falling over time: for example, using the PML8o table, the money's worth falls from 90 per cent to 88 per cent over the period 1994 to 2000. However, on moving to the PML92 table, the money's worth rises from 88 per cent to 96 per cent in 200o. Almost certainly the gradual decline we appear to observe when 
using the PML8o table is due to life insurers pricing in higher life expectancy and anticipating the newer mortality tables on the basis of private information. The only new mortality table which makes little difference is the oo Table, but this is unsurprising since it follows on so quickly from the interim adjustments to the 92 Table. ${ }^{14}$

\section{Table 7: Money's worth 65 year old Male Level CPA, Lives}

\begin{tabular}{|c|c|c|c|c|c|c|c|}
\hline Year & $\begin{array}{l}\text { Summary } \\
\text { Money's } \\
\text { worth of } \\
\text { annuities }\end{array}$ & PML8o & PML92 & $\begin{array}{l}\text { PML92 } \\
\text { short } \\
\text { cohort }\end{array}$ & $\begin{array}{l}\text { PML92 } \\
\text { long } \\
\text { cohort }\end{array}$ & $\begin{array}{l}\text { PNMLoo } \\
\text { short } \\
\text { cohort }\end{array}$ & $\begin{array}{l}\text { PNMLoo } \\
\text { long } \\
\text { cohort }\end{array}$ \\
\hline 1994 & 0.875 & 0.875 & & & & & \\
\hline 1995 & 0.910 & 0.910 & & & & & \\
\hline 1996 & 0.884 & 0.884 & & & & & \\
\hline 1997 & 0.899 & 0.899 & & & & & \\
\hline 1998 & 0.886 & 0.886 & & & & & \\
\hline 1999 & 0.931 & 0.863 & 0.931 & & & & \\
\hline 2000 & 0.951 & 0.876 & 0.951 & & & & \\
\hline 2001 & 0.912 & & 0.912 & & & & \\
\hline 2002 & 0.947 & & 0.860 & 0.920 & 0.975 & & \\
\hline 2003 & 0.908 & & 0.822 & 0.880 & 0.936 & & \\
\hline 2004 & 0.850 & & & 0.824 & 0.876 & & \\
\hline 2005 & 0.860 & & & 0.836 & 0.891 & 0.832 & 0.888 \\
\hline 2006 & 0.852 & & & 0.827 & 0.883 & 0.824 & 0.880 \\
\hline 2007 & 0.823 & & & 0.800 & 0.851 & 0.797 & 0.848 \\
\hline 2008 & 0.855 & & & 0.831 & 0.884 & 0.828 & 0.882 \\
\hline 2009 & 0.879 & & & 0.857 & 0.908 & 0.854 & 0.905 \\
\hline \multicolumn{8}{|l|}{ OVERALL } \\
\hline MW & 0.889 & & & & & & \\
\hline
\end{tabular}

Column labeled PML8o shows money's worth calculated using life expectancy data from the Pensioners Male Lives 8o Tables; PML92 calculates money's worth from the Pensioner Male Lives 92 Tables, with short and long cohort interim adjustments. PNMLoo calculates money's worth from the Pensioner Normal Male Lives oo Tables, with short and long cohort interim adjustments. The first column shows the summary money's worth value for each year, using the appropriate life expectancy figures for the relevant years: where there is more than one estimate for a year the summary column takes simple averages.

\footnotetext{
${ }^{14}$ As we have noted already, the oo Table does not have projections: to calculate these figures we apply the interim adjustments to the realised mortality in 2000. This is a further reason why our two sets of projections are so close.
} 


\section{Figure 12}

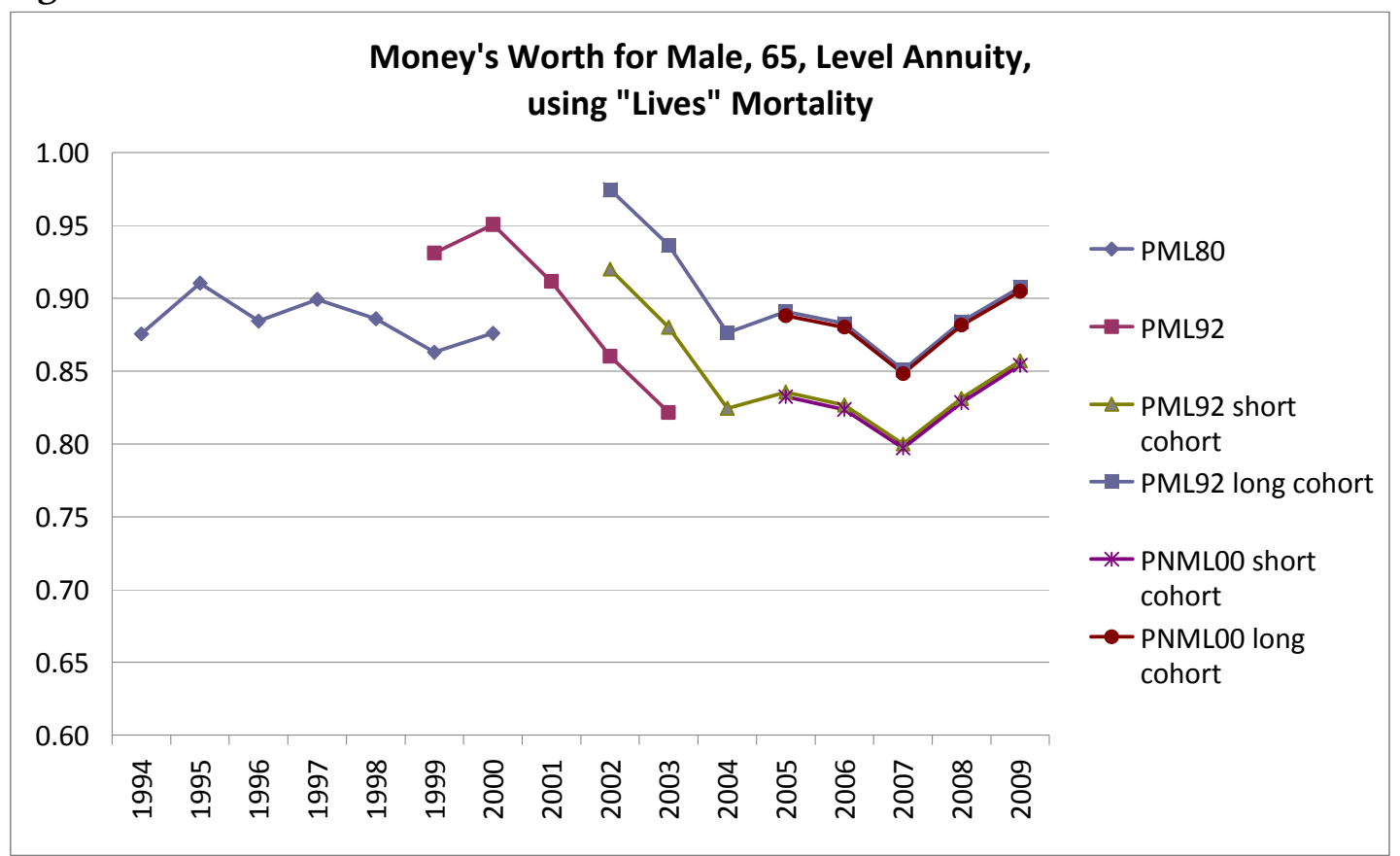

Figure plots the money's worth values from columns 2-7 of Table 7. PML8o refers to Pensioner Male Lives from the 8o Tables, PML92 Pensioner Male Lives from the 92 Tables, Pensioner Male Lives from the 92 Tables with short and long cohort interim adjustments, and Pensioner Normal Male Lives from the oo Tables using short and long cohort interim adjustments.

The first column in Table 7, computes a summary of the money's worth of 65year old males using the combination of life tables in Figure 11, to give our estimate of the change in money's worth over the sample. The money's worth for a 65-year old male has averaged 88.9 per cent over the period 1994-2009. 
Table 8 and Figure 13 shows similar results when the money's worth is based on mortality by amounts. As discussed above, richer people tend to live longer and so when we take an expectation of life weighted by pension size the life expectancy is longer and the money's worth is higher. Using the PMA table, the money's worth is 94 per cent in 1994, falling to between 88 per cent and 93 per cent, depending on whether one uses the short or long cohort assumption. This is uniformly considerably higher than for the figures obtained in the previous Graph using the PML table. From the point of view of the life insurers' profits it is the money's worth weighted by pension that matters and these figures suggest that annuity business has not been excessively profitable. There has been a fall in the money's worth but the change could be consistent more appropriate pricing of the riskiness of annuities due to greater uncertainty over life expectancy. ${ }^{15}$

\footnotetext{
${ }^{15}$ The Board of Actuarial Standards (2008) have recently issued a paper on the uncertainty in forecasts of mortality rates, emphasizing that there is no consensus on the best type of model to use for deriving assumptions about future changes in mortality.
} 
Table 8: Money's worth 65 year old Male Level CPA, Amounts

\begin{tabular}{|c|c|c|c|c|c|c|c|}
\hline Year & $\begin{array}{l}\text { Summary } \\
\text { Money's } \\
\text { worth of } \\
\text { annuities }\end{array}$ & PMA80 & PMA92 & $\begin{array}{l}\text { PMA92 } \\
\text { short } \\
\text { cohort }\end{array}$ & $\begin{array}{l}\text { PMA92 } \\
\text { long } \\
\text { cohort }\end{array}$ & $\begin{array}{l}\text { PNMAoo } \\
\text { short } \\
\text { cohort }\end{array}$ & $\begin{array}{l}\text { PNMAoo } \\
\text { long } \\
\text { cohort }\end{array}$ \\
\hline 1994 & 0.914 & 0.914 & & & & & \\
\hline 1995 & 0.951 & 0.951 & & & & & \\
\hline 1996 & 0.922 & 0.922 & & & & & \\
\hline 1997 & 0.941 & 0.941 & & & & & \\
\hline 1998 & 0.931 & 0.931 & & & & & \\
\hline 1999 & 0.989 & 0.908 & 0.989 & & & & \\
\hline 2000 & 1.011 & 0.923 & 1.011 & & & & \\
\hline 2001 & 0.966 & & 0.966 & & & & \\
\hline 2002 & 0.991 & & 0.911 & 0.963 & 1.018 & & \\
\hline 2003 & 0.950 & & 0.871 & 0.922 & 0.978 & & \\
\hline 2004 & 0.888 & & & 0.862 & 0.914 & & \\
\hline 2005 & 0.892 & & & 0.874 & 0.929 & 0.865 & 0.920 \\
\hline 2006 & 0.884 & & & 0.865 & 0.921 & 0.856 & 0.912 \\
\hline 2007 & 0.852 & & & 0.835 & 0.886 & 0.827 & 0.877 \\
\hline 2008 & 0.885 & & & 0.867 & 0.920 & 0.859 & 0.911 \\
\hline 2009 & 0.910 & & & 0.894 & 0.943 & 0.885 & 0.935 \\
\hline \multicolumn{8}{|l|}{ OVERALL } \\
\hline MW & 0.930 & & & & & & \\
\hline
\end{tabular}

Column labeled PMA8o shows money's worth calculated using life expectancy data from the Pensioners Male Amounts 8o Tables; PMA92 calculates money's worth from the Pensioner Male Amounts 92 Tables, with short and long cohort interim adjustments. PNMAoo calculates money's worth from the Pensioner Normal Male Amounts oo Tables, with short and long cohort interim adjustments. The first column shows the summary money's worth value for each year, using the appropriate life expectancy figures based on amounts of annuities for the relevant years 


\section{Figure 13}

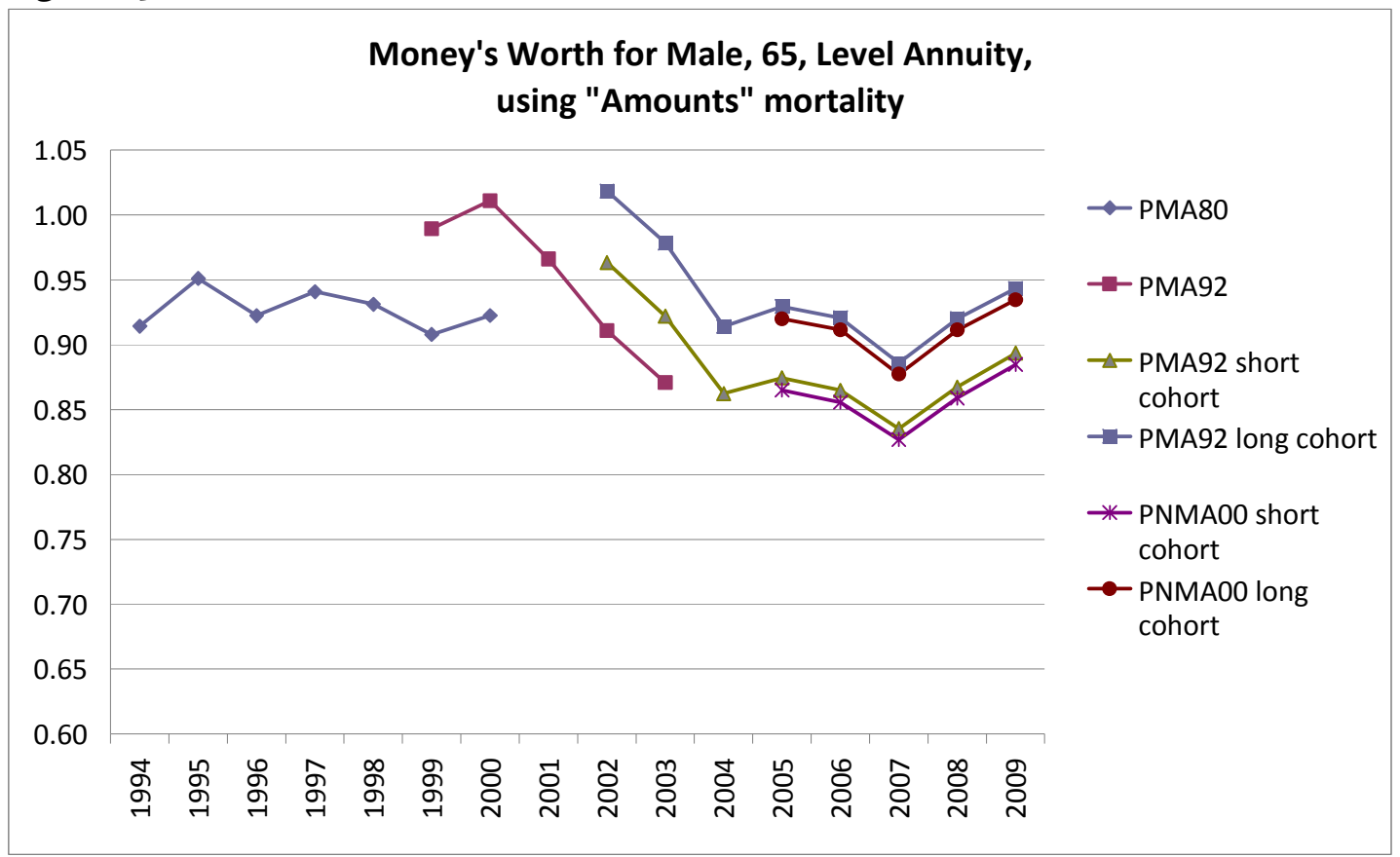

Figure plots the money's worth values from columns 2-7 of Table 8. PMA8o refers to Pensioner Male Amounts from the 8o Tables, PMA92 Pensioner Male Amounts from the 92 Tables, Pensioner Male Amounts from the 92 Tables with short and long cohort interim adjustments, and Pensioner Normal Male Amounts from the oo Tables using short and long cohort interim adjustments.

Table 9 and Figure 14 illustrates similar results for women, although, interestingly women always tend to have higher money's worth, suggesting that the actuaries are underestimating women's life expectancy. The money's worth for a 65-year old female has averaged 89.8 per cent over the period 1994-2009. So although we saw in Section 4 that females at each age receive lower annuity rates than males, the value-for-money of female pension annuities is higher. 
Table 9: Money's worth 65-year old Female Level CPA, Lives

\begin{tabular}{|c|c|c|c|c|c|c|c|}
\hline Year & $\begin{array}{l}\text { Summary } \\
\text { Money's } \\
\text { worth of } \\
\text { annuities }\end{array}$ & PFL8o & PFL92 & $\begin{array}{l}\text { PFL92 } \\
\text { short } \\
\text { cohort }\end{array}$ & $\begin{array}{l}\text { PFL92 } \\
\text { long } \\
\text { cohort }\end{array}$ & $\begin{array}{l}\text { PNFLoo } \\
\text { short } \\
\text { cohort }\end{array}$ & $\begin{array}{l}\text { PNFLoo } \\
\text { long } \\
\text { cohort }\end{array}$ \\
\hline 1994 & 0.891 & 0.891 & & & & & \\
\hline 1995 & 0.931 & 0.931 & & & & & \\
\hline 1996 & 0.897 & 0.897 & & & & & \\
\hline 1997 & 0.924 & 0.924 & & & & & \\
\hline 1998 & 0.918 & 0.918 & & & & & \\
\hline 1999 & 0.920 & 0.895 & 0.920 & & & & \\
\hline 2000 & 0.954 & 0.924 & 0.954 & & & & \\
\hline 2001 & 0.921 & & 0.921 & & & & \\
\hline 2002 & 0.947 & & 0.879 & 0.923 & 0.972 & & \\
\hline 2003 & 0.911 & & 0.843 & 0.886 & 0.937 & & \\
\hline 2004 & 0.868 & & & 0.844 & 0.892 & & \\
\hline 2005 & 0.860 & & & 0.844 & 0.894 & 0.835 & 0.884 \\
\hline 2006 & 0.851 & & & 0.834 & 0.885 & 0.826 & 0.876 \\
\hline 2007 & 0.825 & & & 0.810 & 0.856 & 0.802 & 0.847 \\
\hline 2008 & 0.862 & & & 0.847 & 0.895 & 0.838 & 0.886 \\
\hline 2009 & 0.887 & & & 0.873 & 0.919 & 0.865 & 0.910 \\
\hline \multicolumn{8}{|l|}{ OVERALL } \\
\hline MW & 0.898 & & & & & & \\
\hline
\end{tabular}

Column labeled PFL8o shows money's worth calculated using life expectancy data from the Pensioners Female Lives 8o Tables; PFL92 calculates money's worth from the Pensioner Female Lives 92 Tables, with short and long cohort interim adjustments. PNFLoo calculates money's worth from the Pensioner Normal Female Lives oo Tables, with short and long cohort interim adjustments. The first column shows the summary money's worth value for each year, using the appropriate life expectancy figures for the relevant years. 
Figure 14

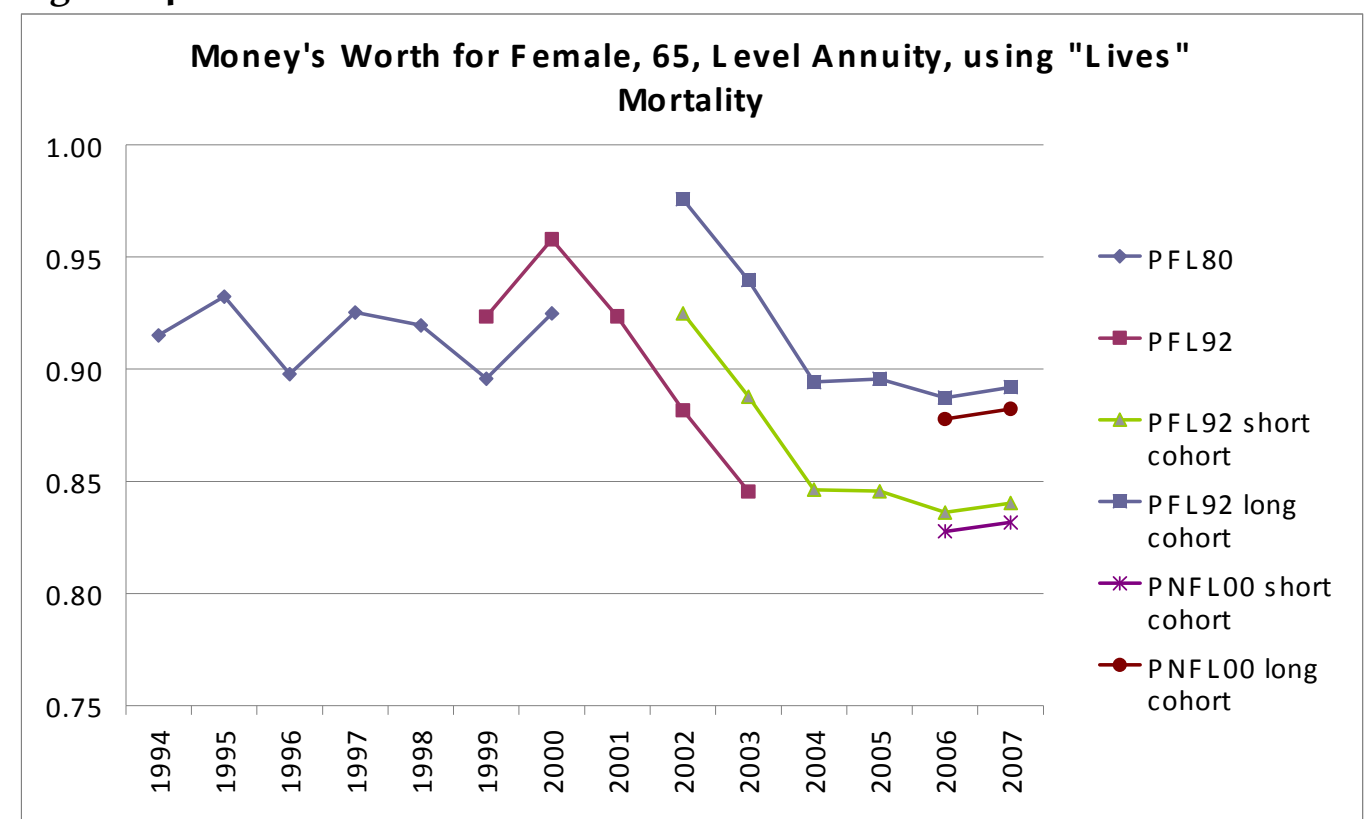

Figure plots the money's worth values from columns 2-7 of Table 10. PFL8o refers to Pensioner Female Lives from the 80 Tables, PFL92 Pensioner Female Lives from the 92 Tables, Pensioner Female Lives from the 92 Tables with short and long cohort interim adjustments, and Pensioner Normal Female Lives from the oo Tables using short and long cohort interim adjustments

Table 10 and Figure 15 turns to RPI-linked or real annuities, for which we only have data for 1999 onwards. The money's worth is always lower for such annuities: compare the money's worth of 94 per cent for a nominal and 90 pence for an RPI-linked annuity for a 65-year old man in 1999. Finkelstein and Poterba (2002) suggest this is due to selection effects, as longer lived people would be more likely to choose real to nominal annuities. However, the discrepancy has more than doubled since 1999: using the oo table with the long cohort projection the money's worth are 9o per cent for nominal and 8o per cent for RPI-linked. It is implausible to suggest that this is entirely due to selection effects and this raises the question of whether other issues, such as higher costs of inflation-proofing annuities, are the major cause of the difference in the money's worth.

Table 10: Money's worth 65-year old Male Real (RPI--linked) CPA, Lives 


\begin{tabular}{|c|c|c|c|c|c|c|c|}
\hline Year & $\begin{array}{l}\text { Summary } \\
\text { Money's } \\
\text { worth of } \\
\text { annuities }\end{array}$ & PML8o & PML92 & $\begin{array}{l}\text { PML92 } \\
\text { short } \\
\text { cohort }\end{array}$ & $\begin{array}{l}\text { PML92 } \\
\text { long } \\
\text { cohort }\end{array}$ & $\begin{array}{l}\text { PNMLoo } \\
\text { short } \\
\text { cohort }\end{array}$ & $\begin{array}{l}\text { PNMLoo } \\
\text { long } \\
\text { cohort }\end{array}$ \\
\hline 1999 & 0.891 & 0.812 & 0.891 & & & & \\
\hline 2000 & 0.876 & 0.794 & 0.876 & & & & \\
\hline 2001 & 0.831 & & 0.831 & & & & \\
\hline 2002 & 0.902 & & 0.797 & 0.864 & 0.940 & & \\
\hline 2003 & 0.856 & & 0.756 & 0.820 & 0.893 & & \\
\hline 2004 & 0.813 & & & 0.777 & 0.850 & & \\
\hline 2005 & 0.779 & & & 0.744 & 0.817 & 0.742 & 0.815 \\
\hline 2006 & 0.768 & & & 0.732 & 0.808 & 0.730 & 0.806 \\
\hline 2007 & 0.754 & & & 0.719 & 0.792 & 0.717 & 0.791 \\
\hline 2008 & 0.816 & & & 0.774 & 0.861 & 0.772 & 0.860 \\
\hline 2009 & 0.759 & & & 0.724 & 0.798 & 0.722 & 0.796 \\
\hline \multicolumn{8}{|l|}{ OVERALL } \\
\hline MW & 0.822 & & & & & & \\
\hline
\end{tabular}

Column labeled PML8o shows money's worth calculated using life expectancy data from the Pensioners Male Lives 8o Tables; PML92 calculates money's worth from the Pensioner Male Lives 92 Tables, with short and long cohort interim adjustments. PNMLoo calculates money's worth from the Pensioner Normal Males Lives oo Tables, with short and long cohort interim adjustments. The first column shows the summary money's worth value for each year, using the appropriate life expectancy figures for the relevant years

\section{Figure 15}

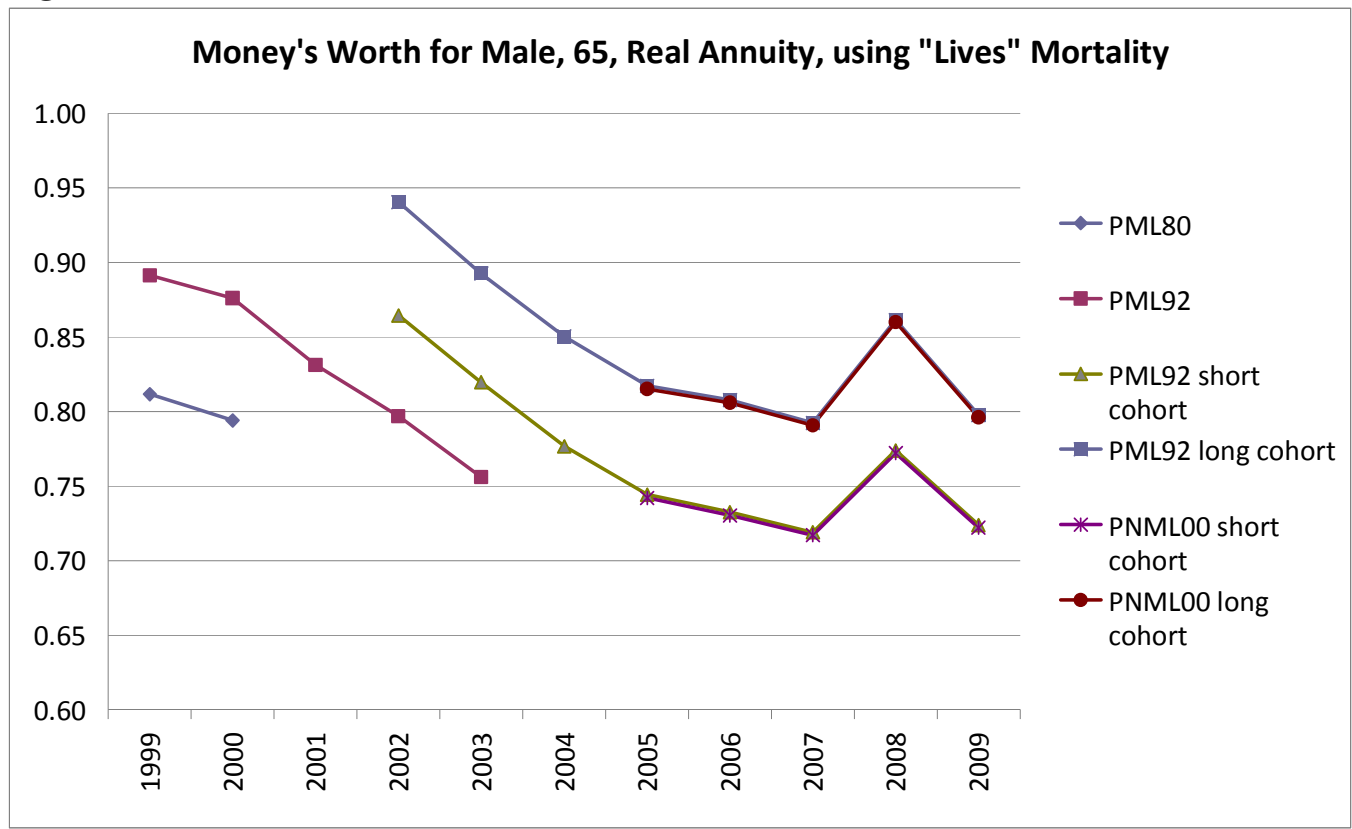

Figure plots the money's worth values from columns 2-7 of Table 11. PML8o refers to Pensioner Male Lives from the 8o Tables, PML92 Pensioner Male Lives from the 92 Tables, Pensioner Male Lives from the 92 Tables with short and long cohort interim adjustments, and Pensioner Normal Male Lives from the oo Tables using short and long cohort interim adjustments 
Table 11 and Figure 16 provide the most dramatic revision to our estimates of the money's worth. In our discussion of life tables we have already seen that there is considerable variation in the life expectancy of different groups of pensioners. Until this point we have continued to follow Finkelstein and Poterba in using Life Office Pensioner mortality to calculate the money's worth. However, although members of occupational pension schemes may top up their pensions with defined contribution AVCs (additional voluntary contributions), these members of defined benefit schemes are likely to have different characteristics to those people who are buying a pension annuity (Cocco and Lopes, 2004; Brander and Finucane, 2007).

Table 11: Money's worth 65-year old Male Level CPA, Various lives assumptions

\begin{tabular}{llllll}
\hline Year & PML92 & $\begin{array}{l}\text { PML92 } \\
\text { long } \\
\text { cohort }\end{array}$ & RMV92 & $\begin{array}{l}\text { RMV92 } \\
\text { long } \\
\text { cohort }\end{array}$ & $\begin{array}{l}\text { PPMoo } \\
\text { long } \\
\text { cohort }\end{array}$ \\
1999 & 0.931 & & 1.001 & & \\
2000 & 0.951 & & 1.026 & & \\
2001 & 0.912 & & 0.978 & & \\
2002 & 0.860 & 0.975 & 0.922 & 1.031 & \\
2003 & 0.822 & 0.936 & 0.883 & 0.992 & \\
2004 & & 0.876 & & 0.926 & \\
2005 & & 0.891 & & 0.943 & 0.946 \\
2006 & & 0.883 & & 0.935 & 0.940 \\
2007 & & 0.851 & & 0.898 & 0.904 \\
2008 & & 0.884 & & 0.933 & 0.941 \\
2009 & & 0.908 & & 0.955 & 0.964
\end{tabular}

Column labeled PML92 shows money's worth calculated using life expectancy data from the Pensioners Male Lives 92 Tables; and from the Pensioner Male Lives 92 Tables, with short and long cohort interim adjustments. RMV 92 calculates money's worth from the Retirement Annuity Contract Males Lives oo Tables, and from the Retirement Annuity Contract Males Lives oo Tables with long cohort interim adjustments; PPMoo calculates money's worth from the Personal Pensioner Males Lives oo Tables with long cohort interim adjustments. 
Figure 16

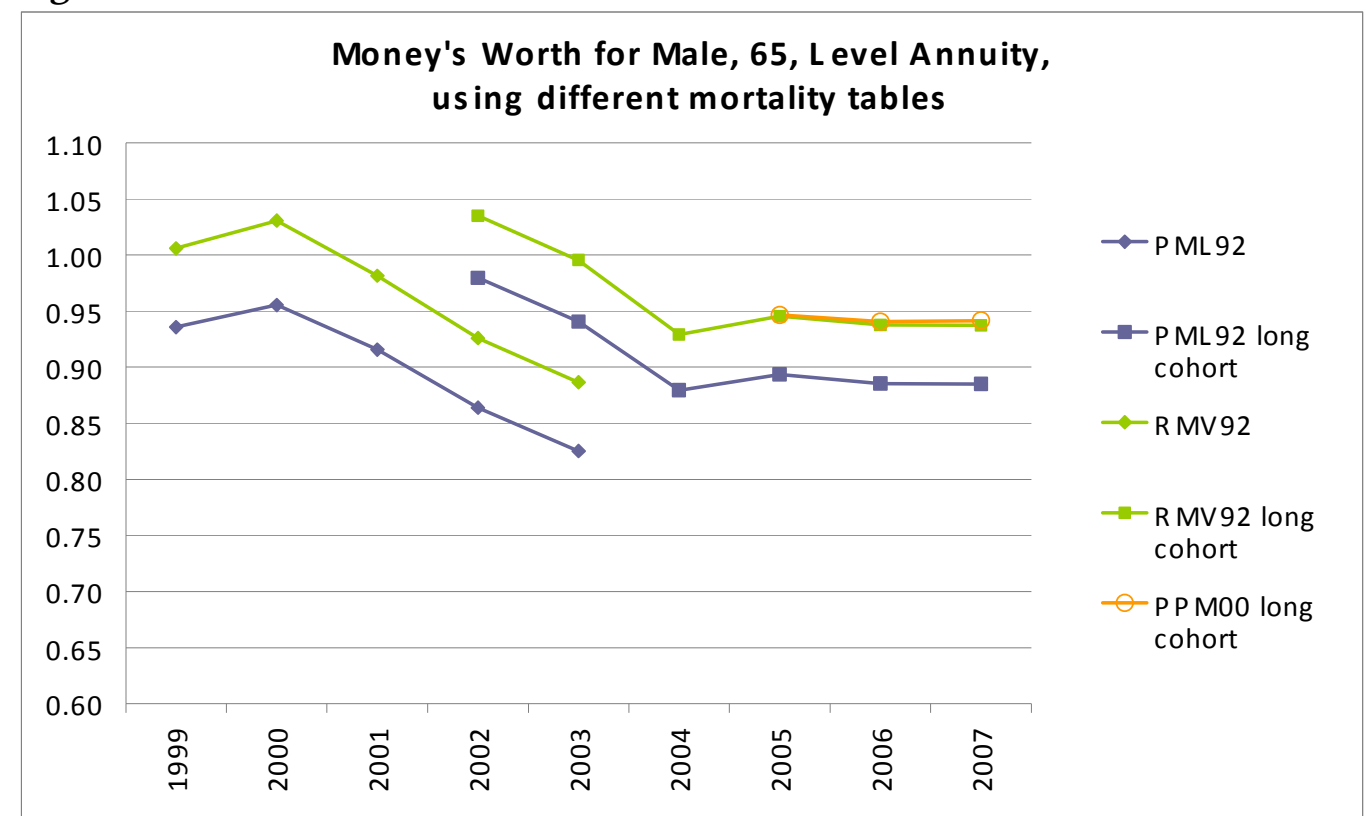

Figure plots the money's worth values from Table 12. PML92 refers to Pensioner Male Lives from the 92 Tables, and from the 92 Tables with long cohort interim adjustments, RMV92 Retirement Annuity Contract from the 92 Tables, and from the 92 Tables with long cohort interim adjustments, PPMoo Personal Pensions Male Lives from the oo Tables with long cohort interim adjustments

So in Table 11 and Figure 16 we now consider the effect of using the mortality of people with Retirement Annuitant Contracts, and for the few years that they are available, the data based on Personal Pensioners. Using these tables adds just over five pence to the money's worth, suggesting that the money's worth was actually greater than one in 2000 and 2002. These figures suggest that annuities have been very good value for the typical annuitant.

The most recent revisions to mortality projections by the actuarial profession have been published (in provisional form) in CMI Working Paper 20. These projections are not provided as a central projection but as a distribution or projections. In other words they attempt to model the uncertainty about the projections (as is conventional in the finance literature). The amount of uncertainty shown by these projections suggests that the $95 \%$ confidence interval for annuity prices (the reciprocal of the money's worth) is about 6 per cent: ie that the money's worth could be up to 3 per cent higher or lower than the central projection. This is clearly a large range of uncertainty. We have not 
incorporated these uncertainties into our projections, because there is some doubt as to whether these are the real ranges of uncertainty - the actuarial profession itself is still looking at new techniques for measuring this.

\section{DISCUSSION}

We conclude our analysis with a brief comparison of our money's worth calculations with the money's worth of other insurance products and then discuss possible explanations for the decline in the money's worth.

\subsection{Evaluation of the money's worth}

The numbers for the money's worth of pension annuities for males have averaged around 90 per cent over the period 1994-2009. As we have discussed in Section 4, it is difficult to evaluate the money's worth figure because we cannot obtain information on the costs of life insurers. One possible means of evaluating money's worth figures is to compare the money's worth on annuities with analogous figures for other forms of insurance. The ABI have provided us with estimates of the premiums paid, and the claims made for a number of insurance markets: motor, domestic property and commercial property insurance over the period 1994-2005. The ratio of the value of claims to premiums paid is a crude measure of the money's worth of these insurance products. We plot these ratios for each year, for level annuities for 65 year-old males, and for the three general insurance products in Figure 17. It can be seen that the money's worth of annuities is consistently higher than the other insurance products. There was only a brief period in the late 1990 s when motor insurance was better value than annuities. 


\section{Figure 18: Money's worth of Annuities and Claims Ratios for Motor, Domestic and Commercial Property Insurance}

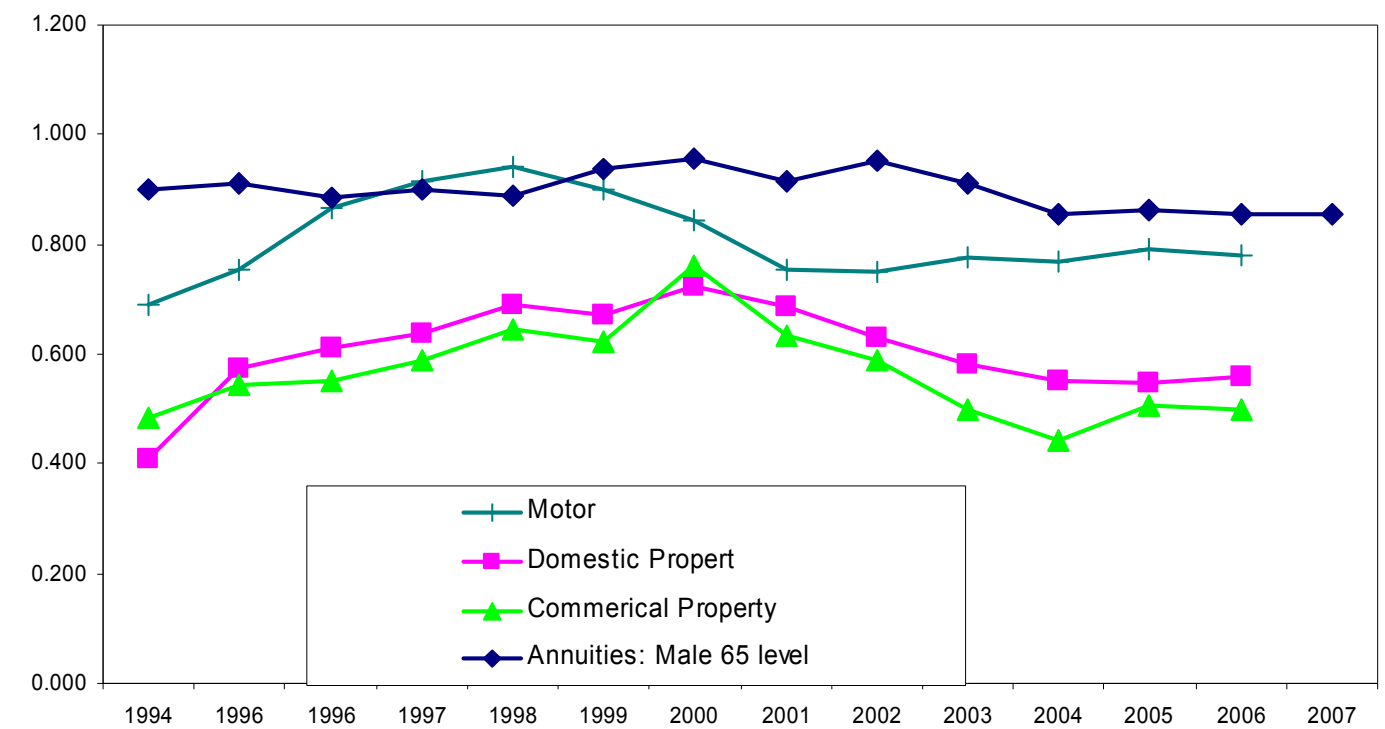

Source: ABI

James (2000) examines the cost of investing in a variety of retail investment products in the $U K$, and finds that to get the market rate of return on $£ 1, a$ consumer would have to invest $£ 1.50$ in a managed fund, and between $£ 1.10$ and $£ 1.25$ in an index tracker. These figures imply a money’s worth of 66 per cent for a managed fund, and less than 91 per cent for a tracker. This suggests that it is during the accumulation phase that charges from the insurance companies have a significant reduction on the effective rate of return and not in the decumulation phase.

\subsection{Possible explanations for the decline in the money's worth}

Notwithstanding the high value for money of annuities relative to other insurance and financial products, the evidence in Figure 12, is that the money's worth of annuities has fallen slightly over the sample. We now discuss various factors that could explain this recent decline:

- Insurance regulation 
- Concentration in the insurance industry

- Insurance cycle

- Pricing of mortality uncertainty

- Impaired lives

\subsubsection{Insurance Regulation}

An important development during the sample period has been the changes to life insurance regulation since 2002. Life insurers in the UK are regulated by the UK's Financial Services Authority (FSA), which incorporates the European Union Life Directives for the insurance industry. As explained in Jordon (2006) the bases of insurance regulation are prudential requirements, meaning that the regulations require insurance companies to have sufficient financial resources to provide for its liabilities. The FSA's General Prudential Sourcebook GENPRU 2.1.8 implements the minimum EU standards for the capital resources required to be held by an insurer undertaking life business. These EU Life Directives set the base capital (currently) at Euros 3.2 million, and the percentage of capital that must be set against technical reserves to cover four risk components: death risks; expense risks; market risks and health risks. In the case of annuities, the amount of capital set aside to cover liabilities is a total of $4 \%$ of the mathematical reserves.

Anticipating a move to a more risk-sensitive EU regulatory approach in the proposed Solvency II, and also because a number of events specific to the UK's insurance industry ${ }^{16}$, the FSA has proceeded with its own risk-based solvency requirements, in part anticipating the likely Solvency II rules (FSA 2003, 2005). This new regime may have increased the regulatory cost associated with providing annuities, by imposing higher levels of regulatory capital on annuity providers. 


\subsubsection{Concentration in the insurance industry.}

We have seen that in Figure 8, although there has been a number of mergers within the life insurance industry over the last ten years, industry concentration has not altered greatly, with the six-firm concentration ratio averaging around 58 per cent since 1985 with no discernable trend. There is no evidence of monopoly pricing within the industry, and the industry has witnessed some new entrants, but the small number of annuity providers remains a potential cause for concern, given the projected increase in annuity demand reported by the Pension Commission in Table 1. The FSA comparative tables provide information on annuity rates in the CPA market, which enables consumers to be kept aware of price dispersion and in principle can use the open-market option to obtain the best annuity rates.

\subsubsection{Insurance Cycle}

There is a wide literature referring to a phenomenon called the "insurance cycle" (surveyed in Harrington, 2004). This refers to the tendency of insurers to increase their premia after periods when negative shocks have resulted in ex post losses, resulting in significant reductions in capital. Since it appears that life insurers may have been making ex post losses on annuities over some of this period, due to unanticipated reductions in mortality (ie when the money's worth was above unity), the observed reductions in annuity rates may be an example of the insurance cycle.

Standard economic theory suggests that insurers would be unable to increase prices to recoup losses after a negative shock, due to competitive pressures. However, more sophisticated theories suggest that increasing premia may be rational: first, the negative shock may have resulted in rational up-dating of probabilities and hence life insurers reduced their projections of mortality by

\footnotetext{
${ }^{16}$ Including the closure of Equitable Life, the Baird Report, the Sandler Review of Medium and Long-term savings in the UK, a number of high profile compliance failings, and the fall in equity values after 2000 .
} 
more than suggested in the CMI reports; secondly, the negative shock would have resulted in a reduction in life insurers' capital on annuities in payment which could not be replaced in the short term, or which could only be replaced at relatively high cost.

\subsubsection{Pricing of mortality uncertainty}

We have already discussed changes in actuarial methodology and how the most recent estimates attempt to include both cohort effects and estimates of the uncertainty in mortality projections. Setting aside the issue of cohort effects, pricing cohort-mortality uncertainty into annuity premia would tend to result in lower annuity rates. For example, suppose the annuity rate was set to be actuarially fair based on the best, or central estimate, of future mortality rates. Then, roughly speaking the life insurer would make a profit about half of the time and a loss about half of the time (with a very small chance of exactly breaking even). In an ideal world the life insurer might hedge this cohort mortality risk, but this would involve payment of a premium and would lower the money's worth since: in fact secondary markets for such risk are negligible, so the life insurer has to bear this risk.

One strategy to cover this risk would be to set an annuity rate so that the life insurer would be 90 per cent sure that enough funds were available to meet the liabilities. This would involve setting an annuity rate based not on the central estimate of future mortality rates, but on the $90^{\text {th }}$ centile of future estimates. Blake, Cairns and Dowd (2007) show how appropriate centiles can be calculated (which they present using "fan charts"). The resulting annuity rate would not be actuarially fair but would limit the risk to the life insurer.

During the period that we have been considering it is probable that life insurers have been paying more explicit attention to cohort mortality risk. Since our money's worth estimates in this paper are based on central estimates, any move 
by life insurers from an actuarially-fair pricing policy to a more conservative pricing policy would appear as a reduction in the money's worth.

In April 2007, the FSA sent a "Dear CEO" letter to chief executives of annuity providers, reflecting on the debate over future annuitant longevity improvements. The letter recognized that companies would usually make assumptions based on their own mortality experiences,

"However, if this is not possible we would expect firms to consider the different industry views in this area and to err on the side of caution" (FSA Dear CEO letter, April 2007

In other words annuity providers, according to the regulator, should price annuities conservatively to reflect the risk of mortality improvements. These concerns on the appropriate pricing on risk, have been echoed by the Governor of the Bank of England in a paper submitted to the Treasury Committee explaining the turmoil in financial markets. The paper concludes that the 2007 credit crisis had been caused by financial institutions under-pricing risk:

"The key objectives remain, ... ensuring that the financial system continues to function effectively, including the proper pricing of risk. If risk continues to be under-priced, the next period of turmoil will be on an even bigger scale. The current turmoil, which has at its heart the earlier under-pricing of risk, has disturbed the unusual serenity of recent years, ..." (King, 2007 [10])

The implication is that institutions should ensure that risk is appropriately priced, to ensure stability of the financial system.

\subsubsection{Impaired Lives}

According to Quinton (2003), there was an increase in the impaired life market of 23 per cent between 2001 and 2002. In 2005, the Synthesis database reports that of $£ 8.5$ billion sales of CPA annuities only $£ 386$ million (4.5 per cent) were impaired life. According to Ainslie (2000), the impaired life annuity market needs a market share of 7.5 per cent per annum to be a viable business model, 
but once it achieves this level, it will have an impact on the profitability of the remaining standard model. Our estimates of money's worth make no allowance for any growth in the impaired life market, since the life tables that we use are unable to distinguish between impaired and non-impaired lives. This growth in the impaired life market would have resulted in the remaining annuitants in the conventional market having average lower mortality. If life insurers priced this information into annuities, they would have been assuming lower mortality than in the standard tables: this could have explained a decline in our measure of the money's worth.

\section{CONCLUSIONS}

This paper has examined a time series of voluntary and compulsory pension annuity rates in the UK for the sample periods 1957-2009 (PLA market) and 1994-2009 (CPA market). The paper computes the money's worth of annuities, and finds that on average the money's worth in the voluntary market over the sample period for 65-year old males has been a very high $98 \%$. In the larger compulsory pension annuity over a shorter sample period we estimate that the money's worth for 65 -year old males has been $89 \%$, and for 65 -year old females has been a similar but slightly larger 90\%. Taking into account load factors associated with annuity contracts and in comparison with other financial and insurance products this implies that annuities are fairly priced. However the value of the money's worth is sensitive to the assumptions made about life expectancy, and we explained the assumptions made about the appropriate life tables to apply to annuitants in the compulsory annuity market. There is some evidence that money's worth has fallen since 2002. We discussed a number of factors that could have effected the fall in money's worth, including: changes in insurance regulation; changes in industrial concentration; life expectancy shocks and the insurance cycle; pricing of mortality uncertainty and the growth in the impaired lives market. 


\section{BIBLIOGRAPHY AND REFERENCES}

Ainslie, R. (2000), “Annuity and Insurance products for impaired lives" Paper presented to the Staple Inn Actuarial Society.

Anderson, N. and J. Sleath (1999), "New estimates of the UK real and nominal yield curves", Bank of England Quarterly Bulletin, 384-92.

Blake, David, Kevin Dowd \& Andrew J.G. Cairns (2007) "Longevity Risk and the Grim Reaper's Toxic Tail: The Survivor Fan Charts" Pensions Institute, Discussion Paper PI-0705

Board for Actuarial Standards, (2008) Discussion Paper on Mortality, March (Financial Reporting Council Ltd)

Brander, J.A. and S. Finucane (2007) "Pensions and Corporate Performance: Effect of the Shift from Defined Benefit to Defined Contribution Pension Plans", Xfi University of Exeter Discussion Paper Number 07/o6

Brown, Jeffrey R., (2001) "Private pensions, mortality risk, and the decision to annuitize", Journal of Public Economics, vol. 82, 29-62.

Brown, Jeffrey R., Mitchell, Olivia S., Poterba, James M. and Warshawsky, Mark J. (2001) The Role of Annuity Markets in Financing Retirement (Cambridge: MIT Press).

Cannon, Edmund, and Tonks, Ian, (2004a) “UK Annuity Rates, Money's Worth and Pension Replacement Ratios 1957-2002", The Geneva Papers on Risk and Insurance, 29(3), pp.394-416.

Cannon, Edmund, and Tonks, Ian (2004b) "UK Annuity Price Series 1957 to 2002," Financial History Review, 11(2), pp.165-196.

Cannon, Edmund, and Tonks, Ian, (2005) Survey of Annuity Pricing, DWP Research Report No. 318.

Cannon, Edmund, and Tonks, Ian, (2009) Moneysworth of Pension Annuities, DWP Research Report No. 563.

Cocco, J. and P. Lopes (2005) "Defined Benefit or Defined Contribution? An Empirical Study of Pension Choices", FMG/UBS London School of Economics Discussion Paper no. 505

Department for Work and Pensions and Inland Revenue Modernising Annuities: A Consultative Document, February 2002. 
Department for Work and pensions (2006) Personal accounts: a new way to save, Presented to Parliament by the Secretary of State for Work and Pensions, December 2006, Cm 695 (HMSO)

Financial Services Authority (2003), "Enhanced Capital Requirements and Individual Capital Assessments for Life Insurers" FSA Consultation Paper 195, August.

Financial Services Authority (2005), Insurance Sector Briefing: Delivering the Tiner Insurance Reforms, April.

Financial Services Authority (2007), “Annuitant longevity improvements" FSA Dear CEO Letter, April.

Finkelstein, Amy and Poterba, James M. (2002) "Selection Effects in the United Kingdom Individual Annuities Market,” Economic Journal, 112(476), pp.28-50.

Finkelstein, Amy and Poterba, James (2004) "Adverse Selection in Insurance Markets: Policyholder Evidence from the U.K. Annuity Market” Journal of Political Economy, 112(1), pp.183-208.

Gompertz, B. (1825) "On the Nature of the Function Expressive of the Law of Human Mortality and a New Mode of Determining Life Contingencies", Philisophical Transactions of the Royal Society of London, 110, 214-94.

Harrington, S.E. (2004) “Tort Liability, Insurance Rates, and the Insurance Cycle”, Brookings-Wharton Papers on Financial Services, 97-138

HM Treasury (2006) The Annuities Market (2006, HMSO)

James, E. (1997) “New Systems for Old Age” World Bank, Working Paper

James, E. and Song Xue (2001) “Annuity Markets Around the World: Money's Worth and Risk Intermediation” CeRP Working Paper 16/o1.

Jordon, K. (2006) "Prudential Regulation under the Financial Services and Markets Act 200o", Chapter 4 in A. Winckler A Practitioner's Guide to the FSA Handbook ( ${ }^{\text {th }}$ Edition, City \& Financial Publishing, Surrey, 2006), pages 133235 .

King, M. (2007) “Turmoil in financial markets: what can central banks do?" Paper submitted to the Treasury Committee, September.

Lee, R. D., and Carter, L. R. (1992) 'Modeling and forecasting U.S. mortality,' Journal of the American Statistical Association, 87, 659-75. 
Makeham, W.M. (1867) "On the Law of Mortality", Journal of the Institute of Actuaries, 13, 325-58.

Mitchell, Olivia S., Poterba, James M., Warshawsky, Mark J. and Brown Jeffrey R. (1999) "New Evidence on the Money's Worth of Individual Annuities," American Economic Review, 89, pp. 1299-1318. This article is reprinted in Brown et al (2001).

Murthi, Mamta, Orszag, J.Michael and Orszag, Peter R. (1999) "The Value for Money of Annuities in the UK: Theory, Experience and Policy," Birkbeck College, London. Discussion Paper.

Pensions Commission (2004), Pensions: Challenges and Choices: The First Report of the Pensions Commission (2004, HMSO)

Pensions Commission (2005), A New Pension Settlement for the Twenty-First Century: The Second Report of the Pensions Commission (2005, HMSO)

Pensions Commission (2006), Implementing an integrated package of pension reforms: The Final Report of the Pensions Commission (2006, HMSO)

Poterba, J. M. (2001) "Annuity Markets and Retirement Security”, Fiscal Studies vol. 22, no. 3, 249-270

Punter Southall (2006) "Developments in the buy-out market" Briefing Note, May (www.puntersouthall.com/UK/tech_bulletins/Brief_Buyout.pdf)

Quinton, P. (2003) 'Enhancing Retirement Income’, Pensions Management, June

Stark, J. (2002) "Annuities: the consumer experience”, ABI Research Report, (ISBN 1-903193-22-2)

Wadsworth, M., Findlater, A. and Boardman, T. (2001) 'Reinventing annuities', (Staple Inn Actuarial Society, 2001).

Wadsworth, M. (2005) The Pension Annuity Market, Association of British Insurers.

Watson-Wyatt (2003) Pension Annuities - Market Dynamics and Implications for Supply, Association of British Insurers.

Warshawsky, Mark J. (1988) "Private Annuity Markets in the United States: 1919-1984," Journal of Risk and Insurance, 55 (3), pp. 518-528. This article is reprinted in Brown et al (2001)

Willets, R. (1999), Mortality in the Next Millennium, (Staple Inn Actuarial Society) 
Yaari, M. (1965) "Uncertain lifetime, life assurance, and the theory of the consumer", Review of Economic Studies, vol. 32, no. 2, 137-50.

\footnotetext{
${ }^{\mathrm{i}}$ Although the relative importance of interest rates of different maturities varies between annuities purchased for different ages

ii If longevity increased so much that annuitants were immortal, the annuity rate and the consol rate would be the same, since the two products would be virtually identical. iii In their analysis of money's worth, Finkelstein and Poterba (2004) use the return on corporate bonds as a deflator rather than government bonds.
} 